Agrupamento baseado em modelos de mistura de gaussianas com covariáveis

\author{
Carlos Eduardo Martins Relvas \\ TESE APRESENTADA \\ $\mathrm{AO}$ \\ INSTITUTO DE MATEMÁTICA E ESTATÍSTICA \\ DA \\ UNIVERSIDADE DE SÃO PAULO \\ PARA \\ OBTENÇÃO DO TÍTULO \\ $\mathrm{DE}$ \\ DOUTOR EM CIÊNCIAS \\ Programa: Doutorado em Ciência da Computação \\ Orientador: Prof. Dr. André Fujita
}

São Paulo, dezembro de 2020 


\section{Agrupamento baseado em modelos de mistura de gaussianas com covariáveis}

Esta versão da Tese contém as correções e alterações sugeridas pela Comissão Julgadora durante a defesa da versão original do trabalho, realizada em 04/12/2020. Uma cópia da versão original está disponível no Instituto de Matemática e

Estatística da Universidade de São Paulo.

Comissão Julgadora:

- Prof. Dr. André Fujita (Presidente) - IME - USP

- Prof. Dr. Alexandre Galvão Patriota - IME - USP

- Prof. Dr. Benilton de Sá Carvalho - UNICAMP

- Prof. Dr. Daniel Yasumasa Takahashi - Universidade Federal do Rio Grande do Norte

- Prof. Dr. Renato Cordeiro de Amorim - University of Essex 


\section{Agradecimentos}

Agradeço, primeiramente, a Deus, que sempre me ajudou durantes minhas conquistas, desde a graduação, mestrado e agora durante o doutorado.

Aos meus pais Marlene e Manuel, minha irmã Ana Paula e meu sobrinho Luiz Carlos, por todo o apoio, carinho e ensinamentos. Devo todas as minhas conquistas a vocês.

À minha esposa Renata e minha filha Julia, por toda a compreensão, o auxílio e o suporte durante todo o projeto. Eu amo vocês!

Ao professor Dr. André Fujita, por todos os ensinamentos e as orientações que foram fundamentais para o desenvolvimento deste trabalho e a minha formação acadêmica.

A todos os professores do Instituto de Matemática e Estatística da Universidade de São Paulo, em especial os do departamento da Estatística e da Ciência da Computação, que sempre estiveram presentes em todos esses anos de IME.

Aos meus sócios Gustavo e Jhonata por toda a compreensão durante a construção deste trabalho.

Aos colaboradores da Datarisk, em especial a equipe de ciência de dados, que me ensinam diariamente.

A todos os meus amigos de graduação e pós-graduação que sempre me ensinaram muito.

A toda a minha família e meus amigos que sempre estiveram presentes. 


\section{Resumo}

Frequentemente, o processo de agrupamento é a primeira etapa em diversos projetos de análises de dados. Ele permite identificar padrões que não foram notados antes, sendo muito útil para detectar novas hipóteses. No entanto, um desafio na análise de dados empíricos é a presença de covariáveis, que podem mascarar a estrutura de agrupamento obtida. Por exemplo: se estamos interessados em agrupar um conjunto de indivíduos em um grupo de controle e pacientes com câncer. Neste caso, o algoritmo de agrupamento poderia agrupar as observações apenas em jovens e velhos. Isso pode acontecer pois a idade do diagnóstico é associada ao câncer. Com isso em mente, desenvolvemos o CEM-Co, um algoritmo baseado em modelos, que remove/minimiza os efeitos das covariáveis durante o processo de agrupamento. Aplicamos o CEM-Co a uma base de dados de expressão gênica, composta de 129 pacientes de câncer de pulmão do estágio I. Como resultado, foi possível identificar um subgrupo de pacientes com taxa de sobrevida estatisticamente menor, algo até então não encontrado.

Palavras chaves: Algoritmo de mistura gaussiana, agrupamento, algoritmo EM, efeitos de covariáveis, BIC, testes de hipóteses. 


\section{Abstract}

Usually, the clustering process is the first step in several data analyses. Clustering allows the identification of unseen patterns and is useful when raising new hypotheses. However, one challenge when analyzing empirical data is the presence of covariates, which may mask the obtained clustering structure. For example: suppose we are interested in clustering a set of individuals into controls and cancer patients. In this case, a clustering algorithm could group subjects into young and elderly. This may happen because, during diagnosis, the age is directly associated with cancer. Thus, we developed CEM-Co, a model-based clustering algorithm that removes/minimizes undesirable covariates' effects during the clustering process. We applied CEM-Co on a gene expression data set composed of 129 stage I non-small cell lung cancer patients. As a result, we identified a subgroup with a poorer prognosis where standard clustering algorithms failed.

Keywords: Mixture Gaussian, Clusterization, EM algorithm, covariates effect, BIC, hyphotesis tests. 


\section{Sumário}

Agradecimentos

Resumo ii

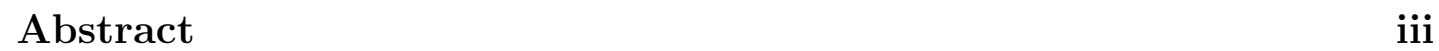

\begin{tabular}{ll}
\hline Introdução & 1
\end{tabular}

\begin{tabular}{lll}
\hline & Motivação & 4
\end{tabular}

1.1 Agrupamento . . . . . . . . . . . . . . . . . . . . . 4

$1.2 \quad$ CEM $\ldots \ldots \ldots \ldots \ldots \ldots$

1.3 Problema $\ldots \ldots \ldots \ldots$

$\begin{array}{lll}2 & \text { Algoritmos de agrupamento com efeitos de covariáveis } & 11\end{array}$

2.1 CEM-dimension . . . . . . . . . . . . . . . . . . . . . . . 11

2.2 CEM-partial . . . . . . . . . . . . . . . . . . . . . . . . 12

2.3 One Step Approach . . . . . . . . . . . . . . . . . . . . . . . . . 13

2.4 Three Step Approach . . . . . . . . . . . . . . . . . . . . . . . . . 14

2.5 Outros métodos . . . . . . . . . . . . . . . . . . . . . . . . . . . . 15

3 CEM-Co - Clustering Expectation Maximization with Covaria$\begin{array}{ll}\text { tes } & 16\end{array}$

3.1 Método . . . . . . . . . . . . . . . . . . . . . . 16

3.2 Estimação . . . . . . . . . . . . . . . . . . . . . . . 18

3.3 Teste de hipótese para efeito das covariáveis . . . . . . . . . . . . 22

3.4 Estimação do número de grupos . . . . . . . . . . . . . . . . . . . 24

3.5 Efeitos não lineares das covariáveis . . . . . . . . . . . . . . . . . 25

3.6 Propriedades . . . . . . . . . . . . . . . . . . . . . . . . . 26

3.7 Implementação . . . . . . . . . . . . . . . . . . . . . . . . . 30

\begin{tabular}{|cc|}
\hline & Simulações \\
\hline
\end{tabular}

4.1 Simulações . . . . . . . . . . . . . . . . . . . . . . . . . . . . 32

4.2 Métodos avaliados . . . . . . . . . . . . . . . . . . . . . . 34

4.3 Métricas . . . . . . . . . . . . . . . . . . . . . . . . . . . . . . . . . . . . 35 
4.4 Resultados . . . . . . . . . . . . . . . . . . . . . . . . 36

4.5 Convergência das estimativas $\ldots \ldots \ldots \ldots$

4.6 Conclusões . . . . . . . . . . . . . . . . . . . . . . . . . . . 45

5 Aplicação Prática 46

5.1 Problema . . . . . . . . . . . . . . . . . . . . . 46

5.2 Dados de estágio I de NSCLC $\ldots \ldots \ldots \ldots$. . . . . . . . . 47

6 Conclusões e Próximos Passos 56

6.1 Conclusões . . . . . . . . . . . . . . . . . . . 56

6.2 Próximos Passos . . . . . . . . . . . . . . . . . . . . 57

\begin{tabular}{ll}
\hline References & 67
\end{tabular} 


\section{Introdução}

Agrupamento é comumente a primeira etapa de várias análises de dados, sendo útil para identificar padrões que não foram notados anteriormente, encontrar excessões ou anomalias e sugerir novas hipóteses. Esses métodos são utilizados em diferentes aplicações; desde análise de dados médicos até dados financeiros ou de comportamento. Isso se deve à sua grande flexibilidade e disponibilidade em diversos softwares. Além disso, os métodos de agrupamento diferem de modelos preditivos supervisionados pois não necessitam de uma variável resposta, o que os torna ainda mais abrangentes.

Apesar da popularidade dos métodos de agrupamento, o conceito de cluster (grupo) ainda não possui um consenso na literatura. Por exemplo: [26] define o grupo como "regiões contínuas contendo uma relativa alta densidade de pontos, separados de outras regiões de pontos por uma área com baixa densidade de pontos". Outro exemplo é a definição de [70], que considera o agrupamento como uma função que depende de uma métrica (distância) entre observações. Em outras palavras, observações que estão perto (distância pequena) são consideradas similares e agrupadas, enquanto que observações que estão longe (distância grande) são agrupadas em grupos diferentes. A primeira definição é parecida com a nossa percepção visual do que é um grupo. Já a segunda é a ideia base de diversos algoritmos de agrupamento.

Devido à variedade da percepção do que define um grupo, existem vários métodos de agrupamento que foram propostos ao longo dos anos. Dentre eles, podemos citar os algoritmos de K-Means, K-Medoids, hierárquicos, CEM-clustering expectation maximization, density-based spatial clustering of applications with noise (DBScan), Spectral Clustering, Mean Shift, Latent Class Analysis $L C A$. Não há, dentre os citados acima, um algoritmo que funcione melhor sempre, visto que cada um foi construído para casos especiais. Eles também apresentam diferentes desempenhos e escalabilidade computacional.

Há algumas situações práticas em que são necessários algoritmos de agrupamento controlando possíveis efeitos de covariáveis. Por exemplo: é muito comum, em análises de dados genéticos, agruparmos pacientes conforme seus diferentes 
genes. No entanto, esse tipo de análise geralmente é feito sem levar em consideração efeitos de outras covariáveis. Suponhamos que os pacientes tenham idades bem diferentes, e que a idade tenha efeito nos genes. Se analisássemos os grupos, formados apenas com base nos dados genéticos, perceberíamos que eles estão enviesados por não terem levado em consideração a idade.

Uma possível solução para o exemplo acima seria realizar a análise de agrupamento separadamente para diferentes faixas etárias e outras covariáveis presentes no problema. No entanto, em geral, esse tipo de análise é feito com uma amostra de dados pequena, o que inviabiliza construir diferentes análises para separar os efeitos.

Portanto, torna-se necessária a existência de métodos de agrupamento em que seja possível controlar efeitos de diferentes covariáveis, bem como encontrar resultados menos enviesados.

Dentre os métodos de LCA, algumas alternativas surgiram ao longo do tempo, com destaque para o one step approach e o three step approach. No entanto, estes métodos removem o efeito das covariáveis de forma superficial ou apenas na média (centroides) dos grupos.

Há ainda os métodos de mixture of experts [49] criados inicialmente para problemas supervisionados, mas que também vêm sendo utilizados para remover efeitos lineares de covariáveis nas médias das distribuições e / ou nas proporções de cada distribuição.

Dado esse cenário, neste trabalho construímos o algoritmo CEM-Co (Clustering Expectation Maximization with Covariates), uma generalização do método CEM (Clustering Expectation Maximization). Este novo método é capaz de remover os efeitos de covariáveis tanto nas médias quanto na estrutura de covariância dos grupos, além de permitir efeitos lineares e não lineares, por meio de splines, nos centroides dos grupos.

Desenvolvemos, além do método em si, as ferramentas para utilização prática, um método para selecionar o número de grupos presentes na análise por meio do Bayesian Information Criterion (BIC), além de um teste de hipóteses para verificar a presença do efeito de cada covariável ou várias covariáveis simultaneamente. Para facilitar o uso do método, desenvolvemos um pacote $R$ que está disponível no $C R A N$ sob o nome de cemco. 
A tese está estruturada em seis capítulos.

No Capítulo 1, mostramos exemplos de problemas de agrupamento em que covariáveis enviesam o resultado para motivar a construção do método desenvolvido neste trabalho.

Já no Capítulo 2, discutimos as principais soluções existentes na literatura hoje, apresentando seus principais pontos fortes e características desejáveis que não possuem.

Toda a teoria, o algoritmo (CEM-Co) e as ferramentas do método desenvolvido neste trabalho (BIC e testes de hipóteses) são apresentados no Capítulo 3. além de algumas provas teóricas das propriedades dos métodos.

Resultados de simulações que mostram algumas propriedades do CEM-Co de forma empírica são apresentados no Capítulo 4 .

No Capítulo 5, realizaremos uma aplicação em uma base de dados transcriptômicos de câncer de pulmão, em que o CEM-Co identificará uma subpopulação com taxa de sobrevida diferente das demais.

Por fim, no Capítulo 6, apresentaremos as conclusões do trabalho desenvolvido, bem como os próximos passos naturais. 


\section{Motivação}

\section{Motivação}

Neste Capítulo discutiremos aplicações comuns de agrupamento, bem como suas limitações na presença de covariáveis.

\subsection{Agrupamento}

Há muitas definições de grupos que foram propostas ao longo dos anos. No entanto, muitas delas são vagas. Tal fenômeno demonstra a dificuldade da definição do termo cluster (grupo), embora seja utilizado intuitivamente e diariamente por nós.

[26] define grupos como "regiões contínuas do espaço contendo relativa alta densidade de pontos separadas de outras regiões com alta densidade por regiões de relativa baixa densidade de pontos". Esta definição é muito próxima da percepção visual que temos de grupos.

Já [70] definem um grupo de maneira diferente. Sendo $\mathbf{X}=\left\{x_{1}, \ldots, x_{N}\right\}$ os nossos dados e $x_{i}$ representando os atributos da $i$-ésima observação. Assim, os autores definem $m$-clustering de $\mathbf{X}$ como a partição de $\mathbf{X}$ em $m$ conjuntos $\left(C_{1}, C_{2}, \ldots, C_{m}\right)$, respeitando as três condições a seguir:

- $C_{i} \neq \emptyset, i=1, \ldots, m$

- $\cup_{i=1}^{m} C_{i}=\mathbf{X}$

- $C_{i} \cap C_{j}=\emptyset, i \neq j ; i, j=1, \ldots, m$

Além disso, as observações contidas em um grupo $C_{i}$ são "mais similares" entre si e "menos similares" às observações em outros grupos. A expressão de similaridade é importante e, como veremos, fundamental nos algoritmos de grupos. Essa medida depende muito do tipo de grupo que queremos formar e do tipo de dados com os quais estamos trabalhando. 
Essa última definição de grupo exige que cada observação pertença a apenas um grupo. Entretanto, há outras definições que atribuem valores diferentes da mesma observação para todos os grupos, como se fosse a "probabilidade" de pertencer a cada grupo. Veremos isso mais adiante ao falarmos sobre o CEM.

Com a definição de grupo, podemos começar a falar dos algoritmos de agrupamento a partir dos dados. Esses algoritmos dividem-se basicamente entre métodos hierárquicos, baseados em centroides, distribuição e densidade.

Os algoritmos hierárquicos consideram que objetos mais próximos devem estar juntos. Portanto, utilizam o conceito de distâncias. Assim, calcula-se a distância entre os pontos. Ao invés de criarmos apenas um conjunto de grupos, geramos um conjunto hierárquico de grupos, sempre unindo pontos mais próximos entre si e fornecendo controle ao usuário para que ele possa escolher os grupos finais.

Métodos baseados em centroides são definidos minimizando a distância de cada ponto com o centroide do grupo mais próximo e recalculando os centroides encontrados. Os métodos baseados em distribuição são algoritmos mais próximos dos conceitos estatísticos, em que grupos podem ser definidos como objetos pertencentes à mesma distribuição de probabilidade.

Por fim, os métodos baseado em densidade definem os grupos como áreas de alta densidade de pontos relativamente a outras regiões do espaço.

Não há dentre os métodos acima, um claro vencedor, que sempre encontra melhores resultados. A escolha do "melhor" método sempre dependerá muito dos tipos de dados e dos problemas.

Algoritmos de agrupamento são extremamente populares dado o seu fácil entendimento pelo público geral ("agrupar observações parecidas") e sua disponibilidade em diversos softwares, facilitando sua utilização. Veremos agora alguns exemplos de diferentes áreas em que algoritmos de agrupamento são utilizados.

Nosso primeiro exemplo é da área de marketing. Diferentes pessoas reagem a um determinado tipo de propaganda de formas distintas. Logo, uma prática muito comum é agrupar estas pessoas de acordo com suas características, como idade, renda, geolocalização entre outras. Com estes grupos de pessoas com mesmas características, são criadas propagandas direcionadas, maximizando assim o retorno da campanha de marketing. 
Em bioinformática, é muito comum o uso de algoritmos de agrupamento com o intuito de agrupar pessoas de acordo com seus genes de forma a identificar diferentes fenótipos clínicos. Assim, pode-se associar os fenótipos aos grupos de genes.

Já em medicina, algoritmos de agrupamento são utilizados, por exemplo, para agrupar antibióticos de acordo com suas propriedades antibacterianas.

Em algumas situações, métodos de agrupamento são utilizados até mesmo como etapas de outros algoritmos. Exemplo disso é a construção de sistemas de recomendação, em que frequentemente algoritmos de agrupamento são utilizados como uma das etapas.

Um último exemplo é a aplicação de algoritmos de agrupamento no mercado financeiro, em que o retorno financeiro de diferentes ações são agrupados para que se possa estudar suas correlações.

Os exemplos citados acima são algumas das inúmeras aplicações existentes hoje com algoritmos de agrupamento.

Na seção abaixo descrevemos um dos algoritmos de agrupamento mais famosos, o CEM. Neste trabalho, ele é generalizado para remover possíveis efeitos de covariáveis para encontrar os grupos.

\subsection{CEM}

O CEM (Clustering Expectation Maximization) ou agrupamento por mistura de gaussianas é construído utilizando uma filosofia um pouco diferente dos métodos discutidos anteriormente, sendo baseado em modelos paramétricos para a formação dos grupos. A ideia consiste em otimizar os parâmetros do modelo de acordo com os dados encontrados. Assim, os grupos são representados por distribuições de probabilidade, sendo mais frequente o uso da distribuição Normal ou de Poisson, dependendo do tipo de dado. Para dados contínuos, utiliza-se a distribuição Normal.

O algoritmo de mistura mais comum considera que cada grupo é representado por uma distribuição normal multivariada com média nos baricentros dos grupos. Sob esta suposição inicial, podemos escrever a densidade de cada um dos $K$ grupos como: 


$$
f_{k}\left(x \mid \mu_{j}, \Sigma_{j}\right)=\frac{1}{\sqrt{(2 \pi)^{d}\left|\Sigma_{j}\right|}} \exp \left(\frac{-\left(x-\mu_{j}\right)^{t} \Sigma_{j}^{-1}\left(x-\mu_{j}\right)}{2}\right),
$$

em que $\mu_{j}$ e $\Sigma_{j}(p \times p)$ representam o vetor $p$-dimensional de média e a matriz de covariância da $j$-ésima distribuição normal multivariada.

Além disso, podemos definir uma probabilidade a priori de cada grupo, que denotaremos por $\alpha_{j}$.

Com estas suposições, podemos encontrar o logaritmo da função de verossimilhança, dada por:

$$
L(x \mid \theta)=\sum_{i=1}^{N} \log \left(\sum_{j=1}^{K} \alpha_{j} f_{j}\left(x_{i} \mid \mu_{j}, \Sigma_{j}\right)\right)
$$

A maximização da função 2 é complexa. Assim, os parâmetros das distribuições $\left(\alpha_{j}, \mu_{j}\right.$ e $\left.\Sigma_{j}\right)$ são encontrados utilizando o algoritmo EM (expectationmaximization).

O algoritmo EM é um processo iterativo que alterna: uma etapa de encontrar o valor esperado da função, usando como estimativa dos parâmetros os valores encontrados no passo anterior do algoritmo; e uma etapa de maximização da função encontrada na etapa de expectation para gerar novas estimativas dos parâmetros do modelo. O algoritmo termina após a convergência.

Para o caso de mistura de gaussianas, descrevemos o algoritmo 1 .

Com os parâmetros estimados, conseguimos encontrar as distribuições de densidade que representam cada grupo e, por consequência, as probabilidades de cada observação pertencer a cada grupo.

Uma vantagem dessa abordagem é o uso de técnicas de inferências estatísticas muito utilizadas na prática e estudadas do ponto de vista teórico. Outro ponto de destaque é termos uma estimativa de uma densidade para cada grupo. Por fim, temos como resultado do algoritmo a probabilidade da observação pertencer a cada grupo, ao invés de apenas assinalar cada observação a um determinado cluster.

Por fim, para uso do algoritmo CEM no software $R$, há o pacote mclust. 


\section{Algorithm 1: CEM.}

Input: as observações $\mathbf{x}_{i}(i=1, \ldots, N)$, o número de grupos $K$.

Output: os $K$ grupos

1 Inicialize aleatoriamente os parâmetros do modelo $\left(\alpha_{j}, \mu_{j}\right.$ e $\Sigma_{j}$, para $j=1,2, \ldots, K)$.

2 Etapa E: Compute as probabilidades a posteriori para todo $i=1, \ldots, N$ e $j=1, \ldots, K$

$$
p_{i, j}=\frac{\alpha_{j} f_{j}\left(x_{i} \mid \mu_{j}, \Sigma_{j}\right)}{\sum_{k=1}^{K} \alpha_{k} f_{k}\left(x_{i} \mid \mu_{k}, \Sigma_{k}^{)}\right.}
$$

3 Etapa M: atualize os parâmetros da seguinte forma (maximização da função anterior):

$$
\alpha_{j}=\frac{\sum_{i=1}^{N} p_{i, j}}{N}, \mu_{j}=\frac{\sum_{i=1}^{N} p_{i, j} x_{i}}{\sum_{i=1}^{N} p_{i, j}}, \Sigma_{j}=\frac{\sum_{i=1}^{N} p_{i, j}\left(x_{i}-\mu_{j}\right)\left(x_{i}-\mu_{j}\right)}{\sum_{i=1}^{N} p_{i, j}},
$$

em que $p_{i, j}$ é a probabilidade da $i$-ésima observação pertencer ao $j$-ésimo grupo.

4 Repetir as etapas 2 e 3 até a convergência.

\subsection{Problema}

Em algumas situações em que algoritmos de agrupamento são utilizados, podem existir covariáveis importantes na análise, isto é, variáveis que não são o interesse principal do estudo, mas cujo efeito impacta diretamente os grupos encontrados utilizando somente as variáveis dependentes.

Por exemplo, no caso da análise de genes, descrito na seção acima, imagine que uma covariável seja a idade. Ou seja: a idade afeta o nível de expressão gênica dos pacientes. Assim, as expressões gênicas são correlacionadas com a idade. Se não levarmos em consideração esse efeito da idade, os grupos encontrados podem não ser ótimos.

Alguns dados foram simulados para exemplificar esse possível problema. Para a covariável idade, simulamos 100 valores de uma distribuição t de Student com 9 graus de liberdade e com média igual a 30. A partir da idade, simulamos, para as 100 observações, em qual de dois possíveis grupos cada uma pertencia utilizando uma distribuição Bernoulli.

Para as observações do primeiro grupo, simulamos valores por meio de uma 

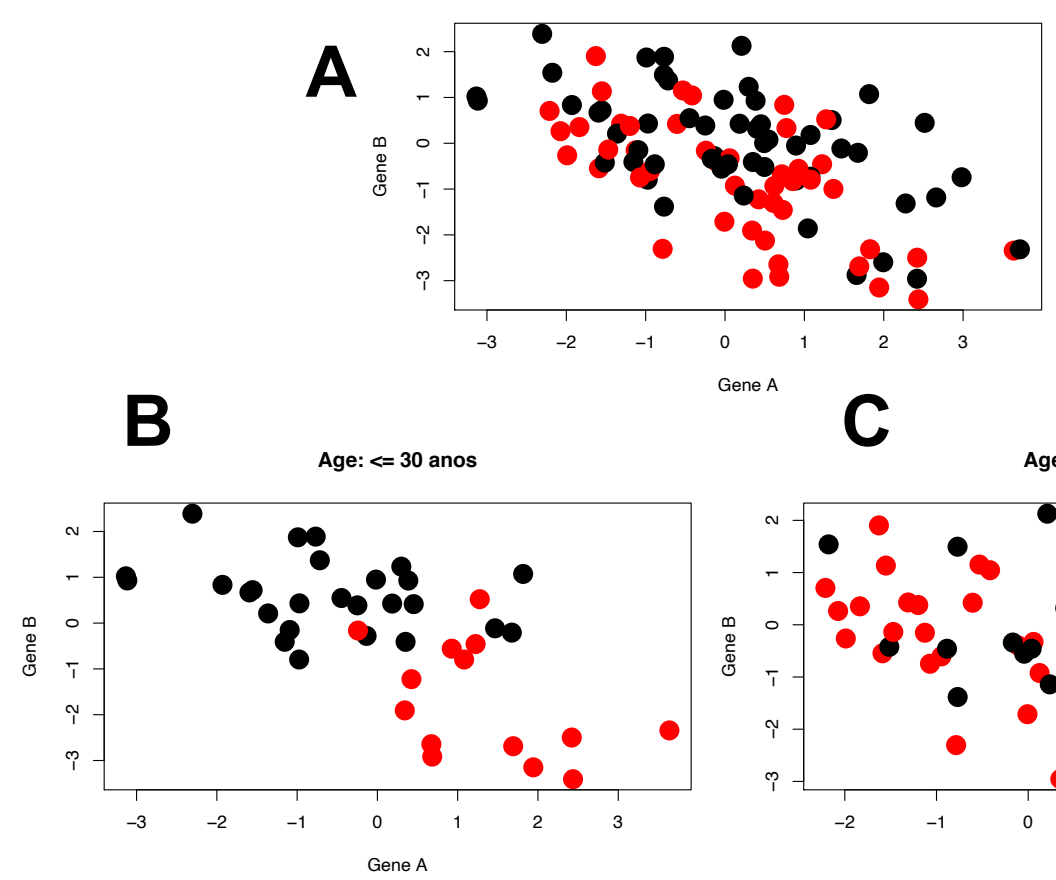

C

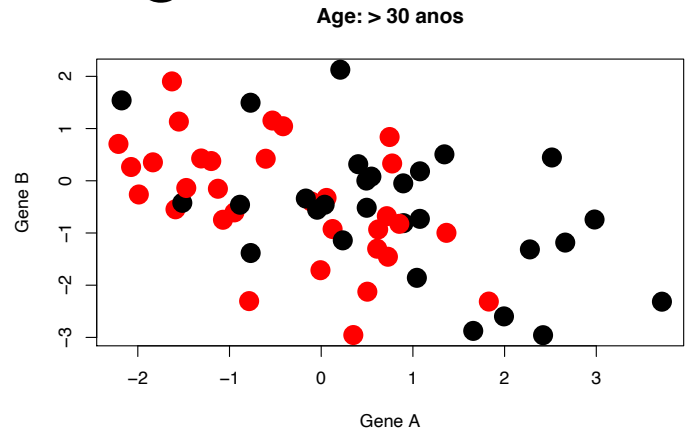

Figura 1: Dados simulados de pacientes com expressão gênica de dois genes, os respectivos grupos e idade. Na imagem A, podemos ver que os dois genes não são suficientes para separar os dois grupos (vermelhos e pretos). $\mathrm{Na}$ imagem B, podemos ver que filtrando pacientes com menos de 30 anos, os dois genes parecem separar os dois grupos (vermelhos e pretos). Por fim, na imagem C, podemos ver que, filtrando pacientes com mais de 30 anos, os dois genes parecem separar os dois grupos (vermelhos e pretos).

distribuição gaussiana multivariada com duas dimensões para representar as expressões gênicas, com médias $\mu_{1}=-4+0.13 I$ e $\mu_{2}=4-0.13 I$, em que $I$ representa a idade. Já para as observações do segundo grupo, utilizamos médias de $\mu_{1}=4-0.1 I$ e $\mu_{2}=-4+0.1 I$. Em ambos os grupos, utilizamos a matriz de identidade como matriz de covariância. Vale ressaltar que a idade é utilizada diretamente na definição dos grupos.

Na Figura 1 A podemos observar esses valores simulados. O primeiro grupo é representado pelo pontos em preto, enquanto que o segundo é representado pelos pontos em vermelho.

Mesmo tendo construções diferentes, com diferentes distribuições gaussianas representando as expressões gênicas, não conseguimos distinguir os grupos 
quando analisamos a Figura 11 A sem controlar pelo efeito da idade.

Já na Figura 11B, apresentamos os mesmos dados, mas apenas considerando as observações com idade menor ou igual a 30 anos. Na Figura 1]C, consideramos as observações restantes, isto é, com mais de 30 anos. Nota-se que, nessas imagens, os grupos (pontos vermelhos e pretos) estão muito mais separados.

Assim, podemos perceber, neste exemplo, que a idade apresenta um efeito muito importante nos grupos; devendo, portanto, ser considerada na análise.

Com este exemplo simulado, fica clara a importância de levarmos em consideração efeitos de covariáveis em métodos de agrupamento. Isso também ocorre em muitas aplicações reais, conforme mostraremos na aplicação deste trabalho, no Capítulo 5.

Analisando esse problema, geralmente, imaginam-se duas possíveis abordagens para resolvê-lo.

A primeira ideia é considerar a idade como uma outra dimensão para o algoritmo de agrupamento. Isto pode não ser suficiente, especialmente em problemas de alta dimensão em que temos diversas variáveis, como expressões gênicas de diferentes genes.

Já a segunda ideia é estimar os grupos para diferentes valores de idade. Por exemplo, poderíamos estimar os grupos para idade menor do que 30 anos e encontrar uma nova estrutura de agrupamento para idades maiores do que 30 anos. O problema dessa abordagem é que estimaríamos as diferentes estruturas dos grupos com menor número de observações, além de aumentar a complexidade caso precisemos quebrar a idade em mais intervalos ou tenhamos mais covariáveis para controlar.

O CEM-Co, método desenvolvido neste trabalho, pode ser visto como a segunda ideia, mas estimando as estruturas de grupos para cada valor diferente das covariáveis simultaneamente com suposições lineares ou não lineares dos efeitos das covariáveis.

No Capítulo 2 discutimos métodos existentes para considerar o efeito de covariáveis na estimação das estruturas dos grupos. Já no Capítulo3, apresentamos o algoritmo CEM-Co criado neste trabalho. 


\section{Algoritmos de agrupamento com efeitos de covariáveis}

\section{Algoritmos de agrupamento com efeitos de covariáveis}

Há diversos métodos de agrupamento que, embora construídos sob diferentes abordagens, não são capazes de remover efeitos de covariáveis, sendo portanto inadequados para o problema introduzido no Capítulo 1.

Neste Capítulo, mostraremos alternativas que são utilizadas em aplicações práticas e também alguns métodos que foram definidos na literatura.

\subsection{CEM-dimension}

Uma alternativa (possivelmente a mais comum e a mais simples) utilizada em aplicações práticas com efeitos de covariáveis é o que denominamos aqui como CEM-dimension.

Nesta abordagem, apenas utilizamos as covariáveis como novas dimensões do espaço para realizar o agrupamento.

Consideraremos $\mathbf{x}_{i}$ o $i$-ésimo vetor $M$ dimensional de variáveis referente à $i$ ésima observação $(i=1, \ldots, N)$, e $\mathbf{z}_{i}=\left(\mathbf{z}_{1, i}, \mathbf{z}_{2, i}, \ldots, \mathbf{z}_{P, i}\right)$ é o vetor de covariáveis associadas com $\mathbf{x}_{i}$. Assim, o CEM-dimension consiste em aplicarmos qualquer algoritmo de agrupamento, em particular o CEM, em $\mathbf{w}_{i}$, em que $\mathbf{w}_{i}=\left(\mathbf{x}_{i}, \mathbf{z}_{i}\right)$ de dimensão $M+P$.

Por utilizar o mesmo algoritmo do CEM, implementado e disponível em diferentes ferramentas, essa alternativa é fácil de se implementar. Por isso, costuma ser a primeira opção pensada para este tipo de problema.

No entanto, ela apresenta algumas suposições importantes. Imaginemos o exemplo dos dados genéticos e a covariável idade, apresentado no Capítulo 1. A covariável idade ou qualquer outra presente no problema terá o mesmo peso 
de qualquer outra variável na definição dos grupos. Este fato nos indica que o uso deste método pode não ser suficiente para realmente remover o efeito das covariáveis no agrupamento, principalmente quando a dimensão dos dados aumenta.

\subsection{CEM-partial}

Uma opção normalmente buscada para tentar solucionar o problema apresentado na Seção 1.3 é o que chamamos de CEM-partial, que consiste nos seguintes passos:

- O primeiro passo seria estimarmos $M$ modelos de regressão linear em que cada dimensão de $\mathbf{x}_{i}$ é definida como a variável resposta do modelo, e utilizarmos todas as covariáveis como variáveis explicativas. Em suma, construiríamos um modelo relacionando cada dimensão de $\mathbf{x}_{i}$ a todas as covariáveis $\left(\mathbf{x}_{, j} \sim \beta_{0}+\beta \mathbf{z}\right.$, com $\mathbf{x}_{, j}$ representando a $j$-ésima dimensão de $\mathbf{x})$.

- A segunda etapa é formada por construir o novo espaço $M$-dimensional, composto pelos resíduos de cada regressão linear $\left(\mathbf{x}_{, j}-\hat{\mathbf{x}}_{, j}\right)$.

- Por fim, com o novo espaço formado pelos resíduos de cada regressão linear, podemos aplicar qualquer método de agrupamento. Por exemplo, o CEM.

Em razão desse procedimento ser formado por uma combinação de regressões lineares e um algoritmo de agrupamento, ele também é facilmente implementado em diferentes ferramentas.

Essa abordagem consiste em tentarmos remover os efeitos das covariáveis de cada variável antes de estimarmos os grupos. Uma das grandes críticas desse procedimento é que assumimos que os efeitos das covariáveis são os mesmos entre todos os grupos. Assim, no exemplo dos dados genéticos, assumiríamos que o efeito da idade nos dados genéticos seria o mesmo independentemente do grupo: uma forte suposição que pode não ser verdade em diferentes aplicações práticas. 


\subsection{One Step Approach}

O método de Latent Class Analysis (LCA) é utilizado para encontrar classes latentes (grupos) a partir de dados multivariados discretos, enquanto que a Latent Profile Analysis (LPA) é utilizado para dados contínuos. Embora sejam métodos criados inicialmente para outros objetivos, [83] foi o primeiro a fazer uma conexão entre Latent Class e agrupamento. E cada vez mais estes métodos são utilizados para este fim.

Apesar de uma nomenclatura própria, o método de LPA é o mesmo do CEM com suposições nas matrizes de covariância. Estes métodos ainda são conhecidos como mixture likelihood approach to clustering, model-based clustering e mixturemodel clustering ([76]).

A extensão desses algoritmos com efeitos de covariáveis foi inicialmente apresentada em [14] e, ao longo dos anos, foram propostos novos algoritmos, destacandose o one step approach e o three step approach [41, sendo estes os mais utilizados atualmente.

A proposta inicial do one step approach [74] é modelar o problema da seguinte forma:

$$
L\left(\theta \mid \mathbf{x}_{1}, \ldots, \mathbf{x}_{N}\right)=\prod_{i=1}^{N} \sum_{j=1}^{K} \alpha_{j}\left(\mathbf{z}_{i}\right) \phi\left(\mathbf{x}_{i}, \mu_{j}, \mathbf{\Sigma}_{j}\right),
$$

em que $\mathbf{x}_{i}, \mathbf{z}_{i}$ foram definidos anteriormente, $\mu_{j}$ e $\boldsymbol{\Sigma}_{j}$ representam a média e a matriz de covariância do $j$-grupo, respectivamente, e $\phi$ representa a função da distribuição normal multivariada. E agora, a priori é modelada em função das covariáveis por meio de um modelo logístico multinomial simples.

Notemos que, com essa proposta, as covariáveis não influenciam os parâmetros dos grupos diretamente, apesar da estimação ser feita conjuntamente, e apenas têm efeito linear nos pesos que definem em qual grupo cada observação pertence. Esta suposição pode inviabilizar o uso do método em várias situações práticas e o método aqui proposto, CEM-Co, a generaliza.

Os críticos [75] desse procedimento apontam quatro fatores para defender o uso do three step approach:

- O uso do one step approach se torna inviável na presença de muitas co- 
variáveis, visto que para cada teste de inclusão e/ou exclusão de covariáveis é necessário re-estimar todo o algoritmo.

- O one step approach adiciona alguns problemas na aplicação como se devemos escolher o número de grupos com ou sem as covariáveis.

- A lógica da maior parte dos pesquisadores é incluir as covariáveis após o agrupamento e não de forma conjunta.

- O one step approach assume que os grupos e a relação com as covariáveis fazem parte do mesmo estágio de desenvolvimento. Em muitas situações práticas, o pesquisador responsável pelo agrupamento pode ser diferente do pesquisador que irá conduzir o teste de correlação com covariáveis.

\subsection{Three Step Approach}

Com as críticas apontadas na Seção 2.3, os pesquisadores de LCA propuseram o three step approach, um procedimento conhecido como classify-and-analyze, sendo composto pelos três passos a seguir:

- Estimamos o método de latent class analysis usual sem levar em consideração nenhuma das possíveis covariáveis presentes na aplicação.

- Com a estimação do passo anterior, agrupamos as observações. Isto pode ser feito assinalando cada observação para o grupo com maior probabilidade (hard clustering) ou apenas usando as probabilidades na próxima etapa (soft clustering).

- Com os grupos definidos, estimamos um modelo de regressão logística multinomial utilizando os grupos como variável resposta e as covariáveis como variáveis explicativas.

Vale apontar que assim como no one step approach, as covariáveis não influenciam os parâmetros dos grupos diretamente e apenas são associadas após os grupos já estarem formados.

Apesar do three step approach não apresentar as críticas apontadas na Seção 2.3. vale ressaltar o agrupamento obtido com este método é idêntico ao obtido 
com o LCA usual. Portanto, este método não apresenta um agrupamento que leva em conta os efeitos das covariáveis, apenas relacionando-as aos grupos obtidos.

Ainda, de acordo com [7], o método do three step approach sobre-estima a relação entre os grupos e as covariáveis. Os autores propõem uma correção conhecida como BCH three step approach. No entanto, as desvantagens de como as covariáveis se relacionam com os grupos, discutidas anteriormente, continuam sendo válidas.

\subsection{Outros métodos}

Outro método proposto para problemas de agrupamento com efeitos de covariáveis é o trabalho de [62] que realiza o agrupamento considerando os efeitos das covariáveis de forma linear ou por meio de um modelo linear misto nos centroides da distribuição gaussiana.

Apesar de ter sido criado para modelos supervisionados, o método de mixture of experts tem sido aplicado para problemas de agrupamento com covariáveis. [19] descreve para dados discretos. Mais recentemente, [38] descreve para dados contínuos com efeitos linear das covariáveis nos centroides das distribuições gaussianas (um caso particular do CEM-Co) e/ou nas probabilidades de cada distribuição. [44] verifica as consequências de não usar o efeito das covariáveis nas probabilidades de cada distribuição, concluindo que tal prática causa um viés pequeno dado o número de parâmetros adicionais necessários para a estimação.

Por fim, mais recentemente, [57] e [58] descrevem um método, similar ao proposto neste trabalho no Capítulo 3, que também é capaz de agrupar as observações considerando os efeitos das covariáveis apenas nos centroides das distribuições de forma linear e generalizando para diferentes estruturas de matrizes de covariância. O trabalho aqui apresentado, além de também permitir efeitos lineares nos centroides, permite efeitos não lineares nos centroides e efeitos lineares nas matrizes de covariância. 


\section{CEM-Co - Clustering Expectation Maximization with Covariates}

\section{CEM-Co - Clustering Expectation Maximi- zation with Covariates}

Neste capítulo, descrevemos o método proposto, bem como suas principais ferramentas.

\subsection{Método}

Consideremos $N, K$, e $P$ os números de itens, grupos e covariáveis, respectivamente; $\mathbf{x}_{i}$ o $i$-ésimo vetor $M$ dimensional de variáveis referentes à $i$-ésima observação $(i=1, \ldots, N)$, e $\mathbf{z}_{i}=\left(\mathbf{z}_{1, i}, \mathbf{z}_{2, i}, \ldots, \mathbf{z}_{P, i}\right)$ é o vetor de covariáveis associadas com $\mathbf{x}_{i}$.

Nosso objetivo é agrupar as $N$ observações $\left(\mathbf{x}_{1}, \mathbf{x}_{2}, \ldots, \mathbf{x}_{N}\right)$ em $K$ grupos removendo o possível efeito das $P$ covariáveis $\left(\mathbf{z}_{1}, \mathbf{z}_{2}, \ldots, \mathbf{z}_{P}\right)$ tanto nas médias quanto na variância dos grupos.

Da mesma forma que o algoritmo clustering expectation-maximization (CEM), CEM-Co assume que cada grupo é representado por uma distribuição normal, e portanto os dados podem ser modelados por uma mistura de distribuições normais.

Sendo $\mu_{j}^{*}(j=1, \ldots, K)$ os centroides dos grupos (as médias das distribuições gaussianas) sem os efeitos das covariáveis e $\beta_{j, l}$ o $M$-dimensional vetor de coeficientes representando a força do $l$-ésimo efeito da covariável $(l=1, \ldots, P)$ no $j$-ésimo centroide do grupo. Portanto, os centroides dos grupos são modelados como:

$$
\mu_{i, j} \mid \mathbf{z}_{i}=\mu_{j}^{*}+\beta_{j, 1} \mathbf{z}_{1, i}+\beta_{j, 2} \mathbf{z}_{2, i}+\ldots+\beta_{j, P} \mathbf{z}_{P, i}
$$


Com o CEM-Co também é possível adicionar efeitos das covariáveis na estrutura de covariância dos grupos. Seja $\mathbf{L}_{i, j}$ a matriz diagonal $M \times M$ em que a $r$-ésima diagonal $(r=1, \ldots, M)$ é $\sigma_{r, j}+\gamma_{1, r, j} \mathbf{z}_{1, i}+\gamma_{2, r, j} \mathbf{z}_{2, i}+\ldots+\gamma_{P, r, j} \mathbf{z}_{P, i}$, e $\mathbf{E}_{j}$ uma matriz positiva definida $M \times M$. Assim, utilizamos a seguinte modelagem para as matrizes de covariâncias das distribuições normais multivariadas de cada grupo como:

$$
\Sigma_{i, j}=\mathbf{L}_{i, j} \mathbf{E}_{j} \mathbf{L}_{i, j}
$$

Vale notar que $\boldsymbol{\Sigma}_{i, j}$ é uma forma da decomposição de Choleski [22], o que implica em uma matriz positiva definida, visto que $\mathbf{E}_{j}$ é positiva definida e utilizamos a matriz diagonal $\mathbf{L}_{i, j}$ duas vezes na equação 5

Outro ponto importante é que caso não exista efeito de covariáveis nas matrizes de covariâncias $\boldsymbol{\Sigma}_{i, j}$ das distribuições gaussianas, basta utilizarmos $\sigma_{r, j}=1 \mathrm{e}$ $\gamma_{l, r, j}=0$ para todos $l=1, \ldots, P, r=1, \ldots, M$, e $j=1, \ldots, K$. Em outras palavras, $\mathbf{L}_{i, j}$ é uma matriz identidade e, consequentemente, a matriz de covariância se torna definida apenas como $\mathbf{E}_{j}$.

Notemos que o número total de parâmetros a se estimar no modelo é definido como $R=K\left(1+(3+P) M+M^{2}\right)$. Assim, dependendo do número de variáveis $(M)$, covariáveis $(P)$ e grupos $(K)$, o número de parâmetros pode ser bem alto, até mesmo maior do que o número de observações $N$. Logo, deve-se ter atenção com isto e, se necessário, utilizar um modelo mais simples, com menos covariáveis ou sem efeito das covariáveis na matriz de covariâncias.

Com as definições acima, podemos definir a função de densidade de uma distribuição normal multivariada como:

$$
\phi\left(\mathbf{x}_{i}, \mu_{i, j}, \boldsymbol{\Sigma}_{i, j}\right)=\frac{\exp \left(-\frac{1}{2}\left(\mathbf{x}_{i}-\mu_{i, j}\right)^{\top} \boldsymbol{\Sigma}_{i, j}^{-1}\left(\mathbf{x}_{i}-\mu_{i, j}\right)\right)}{\sqrt{\operatorname{det}\left(2 \pi \boldsymbol{\Sigma}_{i, j}\right)}} .
$$

Definindo $\alpha_{j}$ como o peso associado ao $j$-ésimo grupo $\left(\sum_{j=1}^{K} \alpha_{j}=1\right)$, podemos escrever a função de verossimilhança como:

$$
L\left(\theta \mid \mathbf{x}_{1}, \ldots, \mathbf{x}_{N}\right)=\prod_{i=1}^{N} \sum_{j=1}^{K} \alpha_{j} \phi\left(\mathbf{x}_{i}, \mu_{i, j}, \Sigma_{i, j}\right)
$$


em que $\theta=\left(\alpha, \mu^{*}, \beta, \mathbf{L}, \mathbf{E}\right)$.

Portanto, podemos escrever a função de log-verossimilhança como:

$$
\ln L\left(\theta \mid \mathbf{x}_{1}, \ldots, \mathbf{x}_{N}\right)=\sum_{i=1}^{N} \ln \sum_{j=1}^{K} \alpha_{j} \phi\left(\mathbf{x}_{i}, \mu_{i, j}, \boldsymbol{\Sigma}_{i, j}\right) .
$$

A estimação de $\theta$ será realizado por máxima verossimilhança, isto é, encontraremos o vetor $\hat{\theta}$ que maximiza a função 7 .

\subsection{Estimação}

A maximização direta da função de log-verossimilhança é difícil por estarmos lidando com o logaritmo de uma soma de exponenciais. Esse tipo de situação é um ótimo exemplo para o uso do algoritmo de expectation-maximization (EM) [51], composto por duas etapas: a etapa de expectation e a etapa de maximization.

Para a construção do algoritmo EM, adicionaremos as variáveis latentes $c_{1,1}$, $\ldots, c_{n, K}$ que indicam a qual grupo cada observação pertence. Assim, $c_{i, j}=1$ indica que o $i$-ésimo elemento pertence à $j$-ésima distribuição gaussiana, $c_{i, j}=0$ indica que o $i$-ésimo elemento não pertence ao $j$-ésimo grupo e portanto $\sum_{j=1}^{K} c_{i, j}=$ 1 para todo $i$. Com estas variáveis latentes, alteramos o objetivo de maximizar a função $L\left(\theta \mid \mathbf{x}_{1}, \ldots, \mathbf{x}_{N}\right)$ para maximizar a função de verossimilhança aumentada $L\left(\theta \mid \mathbf{x}_{1}, \ldots, \mathbf{x}_{N}, c_{1,1}, \ldots, c_{n, K}\right)$, que pode ser escrita como:

$$
L\left(\theta \mid \mathbf{x}_{1}, \ldots, \mathbf{x}_{N}, c_{1,1}, \ldots, c_{n, K}\right)=\prod_{i=1}^{N} \sum_{j=1}^{K} \alpha_{j} \phi\left(\mathbf{x}_{i}, \mu_{i, j}, \boldsymbol{\Sigma}_{i, j}\right) P\left(c_{i, j}=1\right)
$$

Quando as variáveis latentes são conhecidas $c_{i, j}=l$, não temos mais a multiplicação de um somatório na equação acima, visto que o grupo ao qual cada observação pertence é conhecido, e assim, podemos resumir a verossimilhança a

$$
L\left(\theta \mid \mathbf{x}_{1}, \ldots, \mathbf{x}_{N}, c_{1,1}, \ldots, c_{n, K}\right)=\prod_{i=1}^{N} \alpha_{z_{i}} \phi\left(\mathbf{x}_{i}, \mu_{i, z_{i}}, \mathbf{\Sigma}_{i, z_{i}}\right),
$$

em que $z_{i}$ indica em qual grupo a $i$-ésima observação pertence, ou seja, $c_{i, z_{i}}=$ 1. Vale ressaltar que a equação 10 é uma função muito simples de ser maximizada. 
A equação 10 é o que chamamos de função de verossimilhança com dados completos, isto é, com as variáveis latentes $c_{1,1}, \ldots, c_{n, K}$ conhecidas. A maximização da função 10 é a etapa de maximization do algoritmo EM. Porém para podermos maximizá-la, precisamos calcular o valor esperado da função 9 .

Aplicando o logaritmo e calculando a esperança da função 9 em relação a $c_{1,1}, \ldots, c_{n, K}$ chegamos à seguinte expressão:

$$
\begin{array}{r}
E_{C}\left[L\left(\theta \mid \mathbf{x}_{1}, \ldots, \mathbf{x}_{N}, c_{1,1}, \ldots, c_{n, K}\right)\right]= \\
\sum_{k=1}^{K} \sum_{i=1}^{N} \ln \left(\alpha_{k} \phi\left(\mathbf{x}_{i}, \mu_{i, k}, \boldsymbol{\Sigma}_{i, k}\right)\right) P\left(c_{i, k}=1 \mid x_{i}, \theta\right),
\end{array}
$$

em que

$$
P\left(c_{i, k}=1 \mid x_{i}, \theta\right)=\frac{\alpha_{k} \phi\left(\mathbf{x}_{i}, \mu_{i, k}, \mathbf{\Sigma}_{i, k}\right)}{\sum_{l=1}^{K} \alpha_{l} \phi\left(\mathbf{x}_{i}, \mu_{i, k}, \Sigma_{i, k}\right)}
$$

Assim, o algoritmo EM utilizado para a estimação do CEM-Co será composto por um passo de inicialização dos parâmetros e etapas iterativas de expectation e maximization até a convergência das estimativas. A etapa de expectation é equivalente a calcular as probabilidades 11. Já a maximization consiste em maximizar a função no logaritmo da equação 10.

Portanto, baseando-se nas equações 4, 5, 6, e 7 definidas anteriormente, nós podemos simultaneamente estimar os parâmetros $\left(\mu_{j}^{*}, \mathbf{E}_{j}, \sigma_{r, j}, \gamma_{l, r, j}, \beta_{j, l}, \alpha_{j}\right)$ utilizando um algoritmo baseado no algoritmo de expectation-maximization (EM) descrito na etapa 2 .

Por se tratar de um algoritmo EM, assim como o CEM, CEM-Co depende da inicialização na etapa 2 dos parâmetros $\left(\alpha_{j}, \mu_{j}^{*}, \beta_{j, l}, \mathbf{L}_{i, j}, \mathbf{E}_{j}\right.$, for $i=1, \ldots, N$, $j=1, \ldots, K$, e $l=1, \ldots, P)$. Diferentes inicializações podem levar a diferentes valores da função de verossomilhança (algoritmo EM pode encontrar ótimos locais). Portanto, sugerimos rodar o algoritmo 2 várias vezes com diferentes inicializações e selecionar o resultado que apresentar a maior verossimilhança.

Em todos as simulações e aplicações práticas presentes neste trabalho, utilizamos o mesmo processo de inicialização. Para inicializar os parâmetros de cada $r$-ésima variável (dimensão) $(r=1, \ldots, M)$ das observações, estimamos um mo- 
Algorithm 2: Clustering expectation-maximization com efeito das covariáveis tanto nos grupos centroides quanto nas matrizes de covariâncias.

Input: as observações $\mathbf{x}_{i}(i=1, \ldots, N)$, o número de grupos $K$, e as covariáveis $\mathbf{z}_{l, i}(l=1, \ldots, P)$.

Output: os $K$ grupos

1 Seja $\mu_{i, j}$ (Equação 4), $\boldsymbol{\Sigma}_{i, j}$ (Equação 5), $\alpha_{j}$, e $\phi\left(\mathbf{x}_{i}, \mu_{i, j}, \boldsymbol{\Sigma}_{i, j}\right)$ (Equação 6) ser o centroide, a matriz de covariância, o peso associado com a $j$-ésima distribuição normal $(j=1, \ldots, K)$, e a distribuição de densidade normal multivariada, respectivamente.

2 Aleatoriamente inicialize os parâmetros das $K$ distribuições normais, isto é, os centroides $\left(\mu_{j}^{*}\right)$, as matrizes de covariância $\left(\mathbf{E}_{j}, \sigma_{r, j}, \gamma_{l, r, j}\right)$, os efeitos das covariáveis $\left(\beta_{j, l}\right)$, e os pesos para cada distribuição normal $\left(\alpha_{j}\right)(r=1, \ldots, M)$.

3 Expectation step. Calcule a probabilidade esperada para a $i$-ésima observação pertencente ao $j$-ésimo grupo com $P_{i, j}=\frac{\hat{\alpha}_{j} \phi\left(\mathbf{x}_{i}, \hat{\mu}_{i, j}, \hat{\boldsymbol{\Sigma}}_{i, j}\right)}{\sum_{l=1}^{k} \hat{\alpha}_{l} \phi\left(\mathbf{x}_{i}, \hat{\mu}_{i, l}, \hat{\boldsymbol{\Sigma}}_{i, l}\right)}$.

4 Clustering step. Seja $\mathbf{C}$ uma $(N \times K)$ matriz em que $\mathbf{C}_{i, j}=1$ se $\mathbf{x}_{i}$ pertencer ao $j$-ésimo grupo, e $\mathbf{C}_{i, j}=0$, caso contrário. Atualize $\mathbf{C}$ assinalando cada $i$-ésima observação para $j$-ésimo grupo, que apresenta a máxima probabilidade esperada na iteração $P_{i, j}$.

5 Maximization step. Seja $\hat{d}_{i, j}=\hat{\beta}_{j, 1} \mathbf{z}_{1, i}+\hat{\beta}_{j, 2} \mathbf{z}_{2, i}+\ldots+\hat{\beta}_{j, P} \mathbf{z}_{P, i}$ a soma de todos os efeitos das covariáveis. Então, calcule as estimativas de máximo-verossimilhança para $\hat{\mu}_{j}^{*}=\frac{\sum_{i=1}^{N}\left(\mathbf{x}_{i}-\hat{d}_{i, j}\right) \hat{P}_{i, j}}{\sum_{i=1}^{N} \hat{P}_{i, j}}$,

$\hat{\mathbf{E}}_{j}=\frac{\sum_{i=1}^{N} \hat{P}_{i, j}\left(\hat{\mathbf{L}}_{i, j}^{-1}\left(\mathbf{x}_{i}-\hat{\mu}_{j}^{*}-\hat{d}_{i, j}\right)\right)\left(\hat{\mathbf{L}}_{i, j}^{-1}\left(\mathbf{x}_{i}-\hat{\mu}_{j}^{*}-\hat{d}_{i, j}\right)\right)^{\top}}{\sum_{i=1}^{N} \hat{P}_{i, j}}$,

$\hat{\beta}_{j, l}=\frac{\sum_{i=1}^{N} \mathbf{z}_{l, i}\left(\mathbf{x}_{i}-\hat{\mu}_{j}^{*}-\hat{d}_{i, j}+\hat{\beta}_{j, l} \mathbf{z}_{l, i}\right) \hat{P}_{i, j}}{\sum_{i=1}^{N} \mathbf{z}_{l, i}^{2} \hat{P}_{i, j}}$, e $\hat{\alpha}_{j}=\frac{\sum_{i=1}^{N} \mathbf{C}_{i, j}}{N}$. Para estimar o valor máximo da função de verossimilhança, encontre as raízes (ou zeros) da derivada parcial de $\hat{\mathbf{L}}_{i, j}$ utilizando o método de Newton-Raphson.

6 Volte para 3 até a convergência da função de verossimilhança (Equação 7). 
delo de regressão linear utilizando a $r$-ésima variável (dimensão) como a variável resposta e as covariáveis $\left(\mathbf{z}_{l, i}\right)$ como variáveis explicativas. Assim, $\beta_{j, l}$ é inicializado como os coeficientes estimados dos modelos de regressão linear. Notemos que $\beta_{j, l}$ é inicializado da mesma forma para todos $j=1, \ldots, K$ (em outras palavras, inicialmente, os efeitos das covariáveis são os mesmos para todos os grupos. Para inicializar os outros parâmetros, estimamos o algoritmos de agrupamento CEM utilizando os resíduos de todas as regressões como o novo espaço para o agrupamento. Este método de inicialização apresentou bons resultados. No entanto, para diminuir a probabilidade de encontrarmos um ótimo local, criamos algumas perturbações na inicialização, estimando o CEM-Co várias vezes com diferentes inicializações e salvando o melhor resultado.

O algoritmo para inicialização dos parâmetros é descrito no Algoritmo 3 .

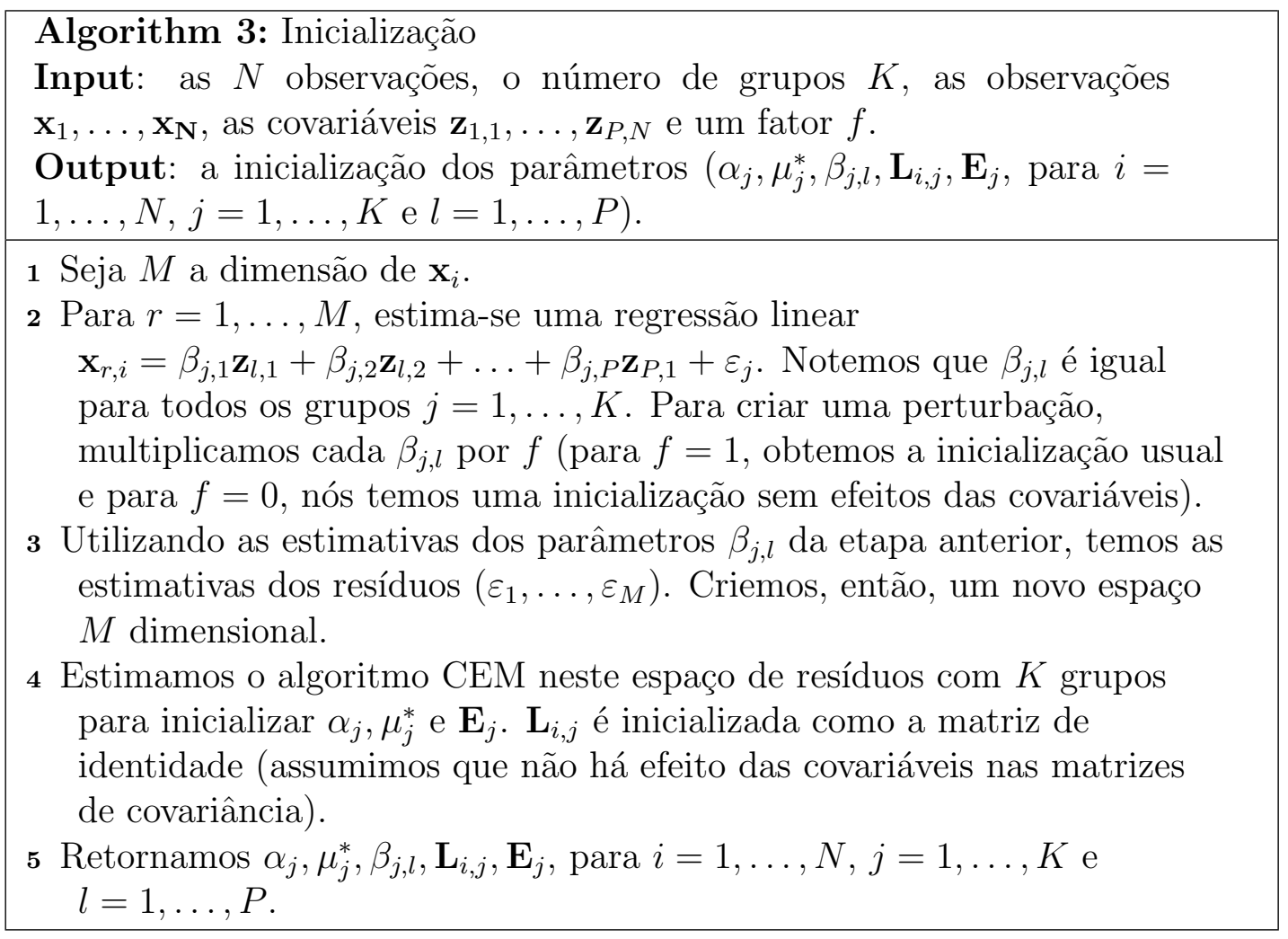

Variando o parâmetro $f$ do Algoritmo 3 , obtemos diferentes valores de inicialização. Por exemplo, para $f=0$, temos o algoritmo do CEM tradicional. Em nossas simulações e aplicação prática, utilizamos 20 valores de $f$, isto é, variamos 
$f$ entre 0 e 2 em intervalos de $0.1(f=0,0.1,0.2, \ldots, 1.9,2)$.

Toda a estimação descrita acima pode ser realizada também supondo-se que não há efeito das covariáveis na matriz de covariância. Neste caso, na etapa 5 do Algoritmo 2 teremos a estimação de $\hat{\mathbf{E}}_{j}$ e sempre consideramos que $\hat{\mathbf{L}}_{i, j}$ será a matriz de identidade.

\subsection{Teste de hipótese para efeito das covariáveis}

Em diferentes aplicações práticas, é de grande interesse a possibilidade de testar se o efeito de uma ou várias covariáveis é estatisticamente associada à estrutura de agrupamento. Assim, é possível verificar se o efeito de uma covariável realmente precisa ser controlado na estimação da estrutura dos grupos.

Por exemplo: vamos supor que queremos testar se o efeito da $l$-ésima covariável $\left(\mathbf{z}_{l}\right)$ não afeta a estrutura dos grupos encontrada. Em outras palavras, teremos o seguinte teste de hipótese:

$H_{0}: \beta_{1, l}=\beta_{2, l}=\ldots=\beta_{K, l}=\mathbf{0}$

versus

$H_{1}$ : Pelo menos um $\beta_{j, l} \neq \mathbf{0}(j=1, \ldots, K)$.

Para realizarmos esse teste de hipótese, utilizamos um teste de razão de verossimilhança (likelihood ratio test), LRT, [82]. Seja $L\left(\alpha_{j}, \mu_{j}^{*}, \beta_{j, l}, \mathbf{L}_{i, j}, \mathbf{E}_{j} \mid \mathbf{x}_{1}, \ldots\right.$, $\mathbf{x}_{N}, \beta_{1, l}=\ldots=\beta_{K, l}=\mathbf{0}$ ) a função de verossimilhança assumindo que o efeito da l-ésima covariável não existe no $j$-ésimo centroide (hipótese nula), e seja $\left.L\left(\alpha_{j}, \mu_{j}^{*}, \beta_{j, l}, \mathbf{L}_{i, j}, \mathbf{E}_{j} \mid \mathbf{x}_{1}, \ldots, \mathbf{x}_{N}\right)\right)$ a função de verossimilhança do modelo sob a hipótese alternativa (Equação 7). Então, podemos definir a estatística do teste (D) como:

$$
\begin{array}{r}
D=2\left\{\ln \left(L\left(\hat{\theta} \mid \mathbf{x}_{1}, \ldots, \mathbf{x}_{N}\right)\right)-\right. \\
\left.\ln \left(L\left(\hat{\theta}_{\mathbf{0}} \mid \mathbf{x}_{1}, \ldots, \mathbf{x}_{N}\right)\right)\right\}
\end{array}
$$

em que $\hat{\theta}_{\mathbf{0}}$ são os coeficientes obtidos pelo estimador de máximo verossimilhança sob $H_{0}\left(\beta_{1, l}=\beta_{2, l}=\ldots=\beta_{K, l}=\mathbf{0}\right)$.

Para encontrarmos $D$, estimamos o algoritmo CEM-Co com (hipótese alternativa) e sem (hipótese nula) a l-ésima covariável e comparamos as duas funções 
de verossimilhança.

A distribuição de probabilidade da estatística do teste $D$ é aproximadamente (assintótico) uma distribuição Qui-Quadrado com graus de liberdade igual ao número de parâmetros da hipótese alternativa menos o número de parâmetros do modelo sob a hipótese nula. Por exemplo, no nosso teste específico $\left(H_{0}: \beta_{1, l}=\right.$ $\left.\beta_{2, l}=\ldots=\beta_{K, l}=\mathbf{0}\right)$, temos $K$ parâmetros a ser estimados para todos $\alpha_{j}, K M$ para todos $\mu_{j}^{*}, K M P$ para todos $\beta_{j, l}, K M^{2}$ para todos $\mathbf{E}_{j}$, e $2 K M$ para cada $\mathbf{L}_{i, j}$. Portanto o número total de parâmetros é $K\left(1+M(3+P)+M^{2}\right)$. Para testar o efeito de uma única covariável, temos $K\left(1+M(2+P)+M^{2}\right)$ parâmetros sob $H_{0}$. Logo, o número de graus de liberdade da distribuição Qui-Quadrado testando apenas uma covariável é igual a $K M$.

Se estivermos utilizando a versão modelo CEM-Co assumindo que não há efeito das covariáveis na matriz de covariância, o procedimento para testar o efeito de uma covariável nos centroides será o mesmo do descrito acima.

Com esse procedimento, também é possível testarmos o efeito de múltiplas covariáveis ao mesmo tempo. Da mesma forma, compararíamos as funções de verossimilhança e apenas os graus de liberdade da distribuição Qui-Quadrado seriam alterados.

Podemos também usar um procedimento similar para testar o efeito da $l$ covariável $\left(\mathbf{z}_{l, i}\right)$ na matriz de covariância, isto é:

$$
H_{0}: \gamma_{l, 1,1}=\gamma_{l, 1,2}=\ldots=\gamma_{l, 1, K}=\gamma_{l, 2,1}=\ldots=\gamma_{l, M, K}=\mathbf{0}
$$

versus

$H_{1}$ : Pelo menos um $\gamma_{l, r, j} \neq \mathbf{0}(j=1, \ldots, K$ and $r=1, \ldots, M)$.

Novamente, para obter $D$, estimamos o algoritmo CEM-Co com (hipótese alternativa) e sem (hipótese nula) o efeito da l-ésima covariável na matriz de covariância, e comparamos as duas funções de verossimilhança. Para este caso, o número de graus de liberdade é também $K M$ (há $K M$ parâmetros $\gamma_{l, 1,1}, \gamma_{l, 1,2}, \ldots$, $\left.\gamma_{l, 1, K}, \gamma_{l, 2,1}, \ldots, \gamma_{l, M, K}\right)$.

Para podermos utilizar a distribuição Qui-Quadrado no teste de razão de verossimilhança, é necessário que a função de verossimilhança siga as condições de regularidade 35.

As provas da maioria das condições de regularidade são diretas para os testes descritos nos parágrafos acima, sendo apenas extensões das provas obtidas com o 
uso do algoritmo CEM tradicional. Para a condição que diz que os parâmetros, no caso, $\beta_{i, l}$ e $\gamma_{l, M, K}$ não podem estar na borda da distribuição, vale comentar que, sob $H_{0}$, esta condição é válida pois $\beta_{i, l}$ e $\gamma_{l, M, K}$ são números reais para qualquer $i, l, M$, e $K$.

\subsection{Estimação do número de grupos}

Conforme descrito no Algoritmo 2, CEM-Co necessita como input o número total de grupos $(K)$. Em algumas situações práticas, realmente sabemos o número de grupos que desejamos. No entanto, na maioria das situações, raramente sabemos ou temos ideia do número de grupos a priori. Logo, nestes casos, é preciso estimarmos o número de grupos a se considerar na análise.

Para estimarmos esse número, propomos o uso do critério de informação Bayesiana (Bayesian Information Criteria) - BIC.

Seja $\hat{L}_{K}$ o valor máximo da função de verossimilhança estimado (Equação 7 ) da estrutura de agrupamento obtida pelo CEM-Co com $K$ grupos, $N$ o número de observações, e $R=K\left(1+(3+P) M+M^{2}\right)$ sendo o número total de parâmetros estimados pelo modelo (discutido na Seção 3.3). Assim, podemos definir o BIC para a estrutura de agrupamento obtida pelo CEM-Co com $K$ grupos como:

$$
\mathrm{BIC}_{K}=\ln (N) R-2 \ln \left(\hat{L}_{K}\right) .
$$

O número de grupos estimado $\hat{K}$ é o valor que minimiza a estatística de BIC acima (Equação 13).

Não podemos usar apenas o valor máximo da função de verossimilhança para estimarmos $\hat{K}$ pois com o aumento de parâmetros, a verossimilhança sempre será maior ou igual. Logo, a ideia do BIC é usar a função de verossimilhança, mas penalizando pelo número total de parâmetros de cada ajuste, visto que se aumentarmos o valor de $K$, aumentamos o número de parâmetros presentes no modelo.

Nas simulações presentes no Capítulo 4, avaliamos a eficiência deste método. Na aplicação prática do Capítulo 5, o número de grupos também foi estimado pelo critério BIC.

É importante ressaltar que há outros critérios na literatura que podem ser 
utilizados para estimar o número de grupos e são facilmente adaptados para o CEM-Co. Podemos, por exemplo, citar o AIC (Akaike information criteria), cross validation e a estatística do Slope [29].

\subsection{Efeitos não lineares das covariáveis}

Em algumas situações, os efeitos das covariáveis não são associados linearmente com os centroides dos grupos. Esta relação pode ser, por exemplo, quadrática ou ter até uma relação sigmoide. Nestes casos, o modelo CEM-Co presente neste Capítulo pode não fazer sentido ou não ser ótimo para a estrutura de agrupamento. Portanto, flexibilizamos o CEM-Co para acomodar esse tipo de efeito nos centroides dos grupos.

Consideremos $f_{j, l}$ a função que representa a força do efeito l-ésima covariável no centroide do $j$-ésimo grupo. Assim, podemos escrever os centroides dos grupos "observado" como:

$$
\mu_{i, j}=\mu_{j}^{*}+f_{j, 1}\left(\mathbf{z}_{1, i}\right)+f_{j, 2}\left(\mathbf{z}_{2, i}\right)+\ldots+f_{j, P}\left(\mathbf{z}_{P, i}\right) .
$$

Para modelar $f_{j, l}$, utilizamos B-spline [20].

Sendo $S$ o número de nós e $B$ os graus do polinômio do $B$-spline, podemos representar $f_{j, l}$ por uma matriz $\mathbf{W}_{j, l}$ (com dimensão $(N \times(S+B))$ ), em que a $i$ ésima linha representa a base do spline do efeito da $l$-ésima covariável na $i$-ésima observação do $j$-ésimo grupo. Definimos a matriz $\mathbf{W}_{j}(N \times(P(S+B)))$ como a combinação de $\mathbf{W}_{j, 1}, \mathbf{W}_{j, 2}, \ldots, \mathbf{W}_{j, P}$ por colunas. Vale notar que, conforme discutido anteriormente, esta representação indica efeitos das covariáveis não lineares apenas nos centroides, e não nas matrizes de covariância.

Para obtermos o algoritmo CEM-Co com efeitos não lineares, substituímos $\mathbf{z}_{l}$ pela base do B-spline representado por $\mathbf{W}_{j, l}$ no Algoritmo 2 ,

Já para testar o efeito de uma única covariável, consideramos o número de graus de liberdade igual a $K M(S+B)$ no teste de razão de verossimilhança. Para testes de múltiplas covariáveis, a mudança é proporcional.

Por fim, para estimarmos o número de grupos utilizando o critério BIC, considera-se o número de parâmetros igual a $K\left(1+M(3+P(S+B))+M^{2}\right)$.

Vale notar que a implementação do algoritmo para a estimação do CEM-Co 
com efeitos não lineares nos centroides é a mesma apresentada anteriormente, apenas substituindo cada covariável pelas bases do $B$-spline criadas para cada covariável.

Poderíamos também estender o CEM-Co para efeitos não lineares nas matrizes de covariâncias dos grupos. No entanto, isso aumenta drasticamente o número de parâmetros e a complexidade da estimação. Além disso, tais efeitos não são comumente encontrados na prática.

\subsection{Propriedades}

O algoritmo CEM-Co herda várias propriedades interessantes do CEM tradicional dado que o algoritmo EM é utilizado em ambos. Dentre tais propriedades, destacamos a monotonicidade e a convergência para um valor estacionário do algoritmo. Nesta seção, apresentaremos as provas para essas duas propriedades.

As demonstrações aqui presentes são muito similares às existentes em [51] para o algoritmo EM mais tradicional. Apenas generalizamos para o CEM-Co.

Para as provas apresentadas aqui, assume-se que as variáveis latentes são independentes.

A primeira propriedade que apresentamos é que o algoritmo do CEM-Co é monotônico. Monotonicidade significa que $L\left(\theta^{k+1}\right) \geq L\left(\theta^{k}\right)$, para $k=0,1$, $2, \ldots$, ou seja, a cada nova iteração dos passos de expectation e maximization, o valor da verossimilhança encontrado é maior.

Theorem 3.1. O Algoritmo de otimização do CEM-Co é monotônico entre as iterações.

Demonstração. seja $\left.g_{c}\left(\mathbf{y} \mid \mathbf{z}_{1}, \ldots, \mathbf{z}_{N}\right) ; \theta\right)$ a distribuição de densidade de probabilidade do vetor aleatório $\mathbf{y}$ representando os dados completos dado os efeitos das covariáveis $(\mathbf{z})$. Ao invés de observarmos os dados completos $\mathbf{y}$, observamos os dados incompletos $\mathbf{x}$, em que $\mathbf{x}=\mathbf{x}(\mathbf{y})$. No nosso caso, os dados completos $(\mathbf{y})$ representam a situação em que sabemos o real grupo de cada observação.

A função de log-verossimilhança completa pode ser escrita como: 


$$
\begin{array}{r}
\log L_{c}\left(\theta \mid \mathbf{x}_{1}, \ldots, \mathbf{x}_{N}, \mathbf{z}_{1}, \ldots, \mathbf{z}_{N}\right)= \\
\left.\log g_{c}\left(\mathbf{y} \mid \mathbf{x}_{1}, \ldots \mathbf{x}_{N}, \mathbf{z}_{1}, \ldots, \mathbf{z}_{N}\right) ; \theta\right)
\end{array}
$$

Em geral, podemos descrever as etapas de expectation e maximization como: E-step: Calcula-se

$$
Q\left(\theta ; \theta^{k}\right)=E_{\theta^{k}}\left(\log L_{c}\left(\theta \mid \mathbf{x}_{1}, \ldots, \mathbf{x}_{N}\right) \mid \mathbf{z}\right)
$$

M-step: Escolhemos $\theta^{k+1}$ que maximiza $Q\left(\theta ; \theta^{k}\right)$ para todo $\theta^{k+1} \in \Omega$.

E sabemos que estas duas etapas são alternadas até a convergência do algoritmo.

Vamos mostrar que a função de verossimilhança dos dados incompletos $L(\theta)$ aumenta monototicamente, isto é,

$$
L\left(\theta^{k+1} \mid \mathbf{x}_{1}, \ldots, \mathbf{x}_{N}\right) \geq L\left(\theta^{k} \mid \mathbf{x}_{1}, \ldots, \mathbf{x}_{N}\right)
$$

, para $k=1,2, \ldots$

Seja,

$$
h\left(\mathbf{y} \mid \mathbf{x}, \mathbf{z}_{1}, \ldots, \mathbf{z}_{N} ; \theta\right)=\frac{g_{c}\left(\mathbf{y} \mid \mathbf{z}_{1}, \ldots, \mathbf{z}_{N} ; \theta\right)}{g\left(\mathbf{x} \mid \mathbf{z}_{1}, \ldots, \mathbf{z}_{N} ; \theta\right)}
$$

a densidade condicional de $\mathbf{Y}$ dado $\mathbf{X}$, em que $\mathbf{Y}$ representa os dados completos e $\mathbf{X}$ representa os dados incompletos. Portanto, podemos re-escrever a função de verossimilhança completa (Equação 14) como:

$$
\begin{array}{r}
L\left(\theta \mid \mathbf{x}_{1}, \ldots, \mathbf{x}_{N}, \mathbf{z}_{1}, \ldots, \mathbf{z}_{N}\right)=\log g\left(\mathbf{x} \mid \mathbf{z}_{1}, \ldots, \mathbf{z}_{N} ; \theta\right)= \\
\log g_{c}\left(\mathbf{y} \mid \mathbf{z}_{1}, \ldots, \mathbf{z}_{N} ; \theta\right)-\log h\left(\mathbf{y} \mid \mathbf{x}, \mathbf{z}_{1}, \ldots, \mathbf{z}_{N} ; \theta\right)= \\
\log L_{c}\left(\theta \mid \mathbf{x}_{1}, \ldots, \mathbf{x}_{N}, \mathbf{z}_{1}, \ldots, \mathbf{z}_{N}\right)-\log h\left(\mathbf{y} \mid \mathbf{x}, \mathbf{z}_{1}, \ldots, \mathbf{z}_{N} ; \theta\right) .
\end{array}
$$

Calculando o valor esperado de ambos os lados da Equação 18 condicional à distribuição de $\mathbf{Y}$ dado $\mathbf{Z}$, obtemos: 


$$
\begin{array}{r}
L\left(\theta \mid \mathbf{x}_{1}, \ldots, \mathbf{x}_{N}, \mathbf{z}_{1}, \ldots, \mathbf{z}_{N}\right)= \\
\left.\left.E_{\theta^{(k)}}\left\{L_{c}\left(\theta \mid \mathbf{x}_{1}, \ldots, \mathbf{x}_{N}\right)\right) \mid \mathbf{z}\right\}-E_{\theta^{(k)}}\left\{\log h\left(\mathbf{Y} \mid \mathbf{x}, \mathbf{z}_{1}, \ldots, \mathbf{z}_{N}\right) ; \theta\right) \mid \mathbf{z}\right\}= \\
\mathbf{Q}\left(\theta ; \theta^{(k)}\right)-\mathbf{H}\left(\theta ; \theta^{(k)}\right)
\end{array}
$$

Utilizando a Equação 19, temos que:

$$
\begin{array}{r}
\log L\left(\theta^{(k+1)} \mid \mathbf{x}_{1}, \ldots, \mathbf{x}_{N}, \mathbf{z}_{1}, \ldots, \mathbf{z}_{N}\right)- \\
\log L\left(\theta^{(k)} \mid \mathbf{x}_{1}, \ldots, \mathbf{x}_{N}, \mathbf{z}_{1}, \ldots, \mathbf{z}_{N}\right)= \\
\left\{\mathbf{Q}\left(\theta^{(k+1)} ; \theta^{(k)}\right)-\mathbf{Q}\left(\theta^{(k)} ; \theta^{(k)}\right)\right\}- \\
\left\{\mathbf{H}\left(\theta^{(k+1)} ; \theta^{(k)}\right)-\mathbf{H}\left(\theta^{(k)} ; \theta^{(k)}\right)\right\}
\end{array}
$$

Nota-se que $\mathbf{Q}\left(\theta^{(k+1)} ; \theta^{(k)}\right)-\mathbf{Q}\left(\theta^{(k)} ; \theta^{(k)}\right) \geq 0$ pois é a própria maximização da função de verossimilhança completa. Sendo assim, resta provar que:

$$
\mathbf{H}\left(\theta^{(k+1)} ; \theta^{(k)}\right)-\mathbf{H}\left(\theta^{(k)} ; \theta^{(k)}\right) \leq 0 .
$$

E temos que para qualquer $\theta$,

$$
\begin{array}{r}
\mathbf{H}\left(\theta ; \theta^{(k)}\right)-\mathbf{H}\left(\theta^{(k)} ; \theta^{(k)}\right)= \\
E_{\theta^{(k)}}\left[\log \left\{\frac{\left.h\left(\mathbf{y} \mid \mathbf{x}, \mathbf{z}_{1}, \ldots, \mathbf{z}_{N}\right) ; \theta\right)}{\left.h\left(\mathbf{y} \mid \mathbf{x}, \mathbf{z}_{1}, \ldots, \mathbf{z}_{N}\right) ; \theta^{(k)}\right)}\right\} \mid \mathbf{z}\right] \\
\leq \log \left[E_{\theta^{(k)}}\left\{\frac{\left.h\left(\mathbf{y} \mid \mathbf{x}, \mathbf{z}_{1}, \ldots, \mathbf{z}_{N}\right) ; \theta\right)}{\left.h\left(\mathbf{y} \mid \mathbf{x}, \mathbf{z}_{1}, \ldots, \mathbf{z}_{N}\right) ; \theta^{(k)}\right)}\right\} \mid \mathbf{z}\right] \\
=\log \int_{\chi(\mathrm{z})} H\left(\mathbf{y} \mid \mathbf{x}, \mathbf{z}_{1}, \ldots, \mathbf{z}_{N} ; \theta\right) d \mathbf{y} \\
=0
\end{array}
$$

em que a desigualdade é uma consequência tanto da desigualdade de Jensen's quanto da concavidade da função logarítmica. 
Theorem 3.2. O Algoritmo de otimização do CEM-Co converge para uma sequência estacionária.

Demonstração. vamos provar que o algoritmo do CEM-Co converge para uma sequência estacionária, isto é, que $L\left(\theta^{k}\right)$ converge monotonicamente para algum valor $L^{*}=L\left(\theta^{*}\right)$, em que $L^{*}$ é um valor estacionário em quase todas as aplicações, e que $\theta^{*}$ é o valor que

$$
\frac{\partial L(\theta)}{\partial \theta}=0
$$

Vale lembrar que podemos escrever a função de verossimilhança como a Equação 19. Diferenciando ambos os lados desta equação, obtemos:

$$
\begin{array}{r}
\frac{\partial \log L\left(\theta \mid \mathbf{x}_{1}, \ldots, \mathbf{x}_{N}, \mathbf{z}_{1}, \ldots, \mathbf{z}_{N}\right)}{\partial \theta}= \\
\frac{\partial \mathbf{Q}\left(\theta ; \theta^{k}\right)}{\partial \theta}-\frac{\partial \mathbf{H}\left(\theta ; \theta^{k}\right)}{\partial \theta} .
\end{array}
$$

Na demonstração do Teorema 3.1, provamos que $\mathbf{H}\left(\theta ; \theta^{k}\right) \leq \mathbf{H}\left(\theta^{k} ; \theta^{k}\right)$ para todo $\theta$. Então,

$$
\left[\frac{\partial \mathbf{H}\left(\theta ; \theta^{k}\right)}{\partial \theta}\right]=0
$$

Podemos escrever a Equação 24 para algum $\theta_{\mathbf{0}}$ arbitrário como:

$$
\begin{array}{r}
\frac{\partial \log L\left(\theta=\theta_{\mathbf{0}} \mid \mathbf{x}_{1}, \ldots, \mathbf{x}_{N}, \mathbf{z}_{1}, \ldots, \mathbf{z}_{N}\right)}{\partial \theta}= \\
{\left[\frac{\partial \mathbf{Q}\left(\theta ; \theta_{0}\right)}{\partial \theta}\right] .}
\end{array}
$$

Suponhamos que $\theta_{\mathbf{0}}$ é um ponto estacionário da função de verossimilhança, então 


$$
\begin{array}{r}
\frac{\partial \log L\left(\theta=\theta_{\mathbf{0}} \mid \mathbf{x}_{1}, \ldots, \mathbf{x}_{N}, \mathbf{z}_{1}, \ldots, \mathbf{z}_{N}\right)}{\partial \theta}= \\
{\left[\frac{\partial \mathbf{Q}\left(\theta ; \theta_{0}\right)}{\partial \theta}\right]_{\theta=\theta_{0}}=0 .}
\end{array}
$$

Utilizando a proposição de $\mathrm{Wu}$ [84], que diz que

$$
\sup _{\theta \in \Omega} \mathbf{Q}\left(\theta ; \theta_{0}\right) \geq \mathbf{Q}\left(\theta_{0} ; \theta_{0}\right)
$$

para qualquer ponto estacionário $\theta_{0}$ que não seja um máximo local e as condições de regularidade [51] asseguram que todos os pontos limite de qualquer solução de algoritmo CEM-Co são máximos locais e, portanto, $L\left(\theta^{k}\right)$ converge monotonicamente para algum máximo local.

\subsection{Implementação}

A estimação dos parâmetros do método descrito neste capítulo, bem como o teste de hipótese, a estimação do número de grupos e a possibilidade de efeitos não lineares foi implementada como um pacote no software $R$.

O pacote está disponível de forma open source no respositório do $R(C R A N)$ com o nome cemco (https://cran.r-project.org/web/packages/cemco/index. html) e disponível para download.

Todas as simulações e aplicações práticas presentes neste trabalho foram realizadas utilizando o pacote $R$. Vale ressaltar que o pacote $R$ foi implementado com a possibilidade de ser executado em paralelo por múltiplos processadores (cores), o que acelera o processo de estimação, bem como o fato de ser treinado com diferentes inicializações.

As principais funções do pacote são CemCO e CemCOVar, que ajustam, respectivamente, o CEM-Co com e sem efeitos das covariáveis nas matrizes de covariância, em que o usuário passa como input das funções os dados que se deseja agrupar, as covariáveis e o número de grupos. 


\section{Simulações}

\section{Simulações}

Neste capítulo apresentamos os resultados obtidos utilizando diferentes cenários de simulações para mostrar a eficiência do CEM-Co e entender algumas de suas propriedades com dados empíricos.

\subsection{Simulações}

Para avaliar a performance do CEM-Co no agrupamento das observações, o poder do teste de razão de verossimilhança e a acurácia do BIC em estimar o número de grupos, testamos três cenários diferentes:

Cenário 1: efeito linear das covariáveis nos centroides dos grupos.

1. Escolhemos o número de grupos igual a $2(K=2)$, a dimensão dos dados igual a $5(M=5)$ e o número de covariáveis igual a $5(P=5)$.

2. Fixamos os centroides (médias) dos grupos $(K=2)$ iguais a $\mu_{1}^{*}=(0,0,0$, $0,0)$ e $\mu_{2}^{*}=(0.2,0.2,0.2,0.2,0.2)$.

3. Os efeitos das covariáveis em cada grupo $(\beta)$ foram escolhidos para que sejam os mesmos dos valores estimados para a aplicação real com os dados do câncer de pulmão (ver Capítulo 5).

4. Para cada observação $(i=1, \ldots, N)$, simulamos $P=5$ covariáveis, duas a partir de uma distribuição normal com média zero e variância igual a um $\left(\mathbf{z}_{1, i} \sim N(0,1), \mathbf{z}_{2, i} \sim N(0,1)\right)$ e três a partir de distribuições Bernoullis com parâmetros iguais a 0.4,0.25, e $0.15\left(\mathbf{z}_{3, i} \sim B(0.4), \mathbf{z}_{4, i} \sim B(0.25)\right.$, $\left.\mathbf{z}_{5, i} \sim B(0.15)\right)$.

5. Por fim, simulamos $N / 2$ observações para cada grupo a partir de uma distribuição gaussiana multivariada com médias iguais a $\mu_{i, j}=\mu_{j}^{*}+\beta_{1, j} \mathbf{z}_{1, i}+$ $\beta_{2, j} \mathbf{z}_{2, i}+\beta_{3, j} \mathbf{z}_{3, i}+\beta_{4, j} \mathbf{z}_{4, i}+\beta_{5, j} \mathbf{z}_{5, i}($ para $i=1, \ldots, N / 2$ e $j=1,2)$ e com 
matriz de covariância igual a uma matriz identidade $(5 \times 5)$ multiplicada por 0.03 para cada grupo.

Cenário 2: efeitos lineares das covariáveis tanto nos centroides dos grupos quanto nas matrizes de covariância.

1. Neste caso, escolhemos o número de grupos igual a $4(K=4)$, o número de dimensões iguais a $2(M=2)$, e o número de covariáveis igual a $1(P=1)$.

2. Os centroides (médias) dos 4 grupos $K=4$ foram fixados iguais a $\mu_{1}^{*}=$ $(0,0), \mu_{2}^{*}=(0,1), \mu_{3}^{*}=(1,0)$, e $\mu_{4}^{*}=(1,1)$.

3. Já os efeitos da covariável nos centroides foram escolhidos como $\beta_{1}=$ $(0.3,0.3), \beta_{2}=(-0.3,-0.3), \beta_{3}=(0.3,-0.3)$ e $\beta_{4}=(-0.3,0.3)$.

4. A covariável foi simulada para cada observação a partir de uma distribuição gaussiana com média igual a 1 e variância igual a $1\left(\mathbf{z}_{1, i} \sim N(1,1)\right)$.

5. Para o efeito na matriz de covariância, seja $\mathbf{E}_{j}$ uma matriz $(2 \times 2)$ com 0.1 na diagonal, $\sigma_{r, j}=1$ (for $r=1,2$ e $\left.j=1,2,3,4\right), \gamma_{1, r, j}=w_{j}(\operatorname{para} r=1,2$, $w_{1}=1, w_{2}=1, w_{3}=1$, e $\left.w_{4}=10\right)$, e $\mathbf{L}_{i, j}$ uma matriz $(2 \times 2)$ da mesma forma que foi definida na Seção 3.1 . Com estes parâmetros, simulamos $N / K$ observações de uma distribuição gaussiana multivariada com média e matriz de covariância igual a $\mu_{i, j}=\mu_{j}^{*}+\beta_{j} \mathbf{z}_{1, i}$ e $\boldsymbol{\Sigma}_{i, j}=\mathbf{L}_{i, j} \mathbf{E}_{j} \mathbf{L}_{i, j}$, respectivamente, para cada grupo $j=1, \ldots, K$.

Cenário 3: covariáveis com efeitos não lineares nos centroides dos grupos. Para simular esse efeito não linear, utilizamos como base o cenário 2 e modificamos a etapa 5 para:

1. Seja $f_{j, 1}\left(\mathbf{z}_{1, i}\right)=\beta_{j} \mathbf{z}_{1, i}+\beta_{j} \mathbf{z}_{1, i}^{2}$ uma função quadrática representando a força do efeito da covariável no centroide do $j$-ésimo grupo. Então, simulamos $N / K$ observações de uma distribuição normal multivariada com média iguais a $\mu_{i, j}=\mu_{j}^{*}+f_{j, 1}\left(\mathbf{z}_{1, i}\right)$, e uma matriz de covariância $(2 \times 2)$ representada pela identidade multiplicada por 0.1 , para cada grupo $j=1, \ldots, K$. Vale apontar que utilizamos o mesmo valor $\beta_{j}$, definido no cenário 2 , duas vezes na fórmula quadrática. 
Para o cenário 1, os números de observações simulados foram $N=120,240$, e 360 para entendermos o impacto do tamanho amostral. Para os cenários 2 e 3, os números foram $N=200,300,400$, e 800 . No cenário 3 , modelamos a função $f_{j, 1}$ com $B$-spline cúbico com quatro graus de liberdade.

Para cada cenário e para tamanho amostral, repetimos os experimentos 300 vezes (300 réplicas), visando checar as propriedades do CEM-Co nestes diferentes cenários.

Vale ressaltar que o cenário 1 foi desenhado para ser muito similar aos dados da aplicação real de câncer, apresentando mais evidências da confiabilidade dos resultados obtidos.

\subsection{Métodos avaliados}

Com os dados simulados descritos na Seção 4.1, comparamos o método CEM-Co com três alternativas comumente utilizadas em problemas de agrupamento com covariáveis, descritas abaixo:

1. CEM: aplicamos o algoritmo padrão clustering expectation-maximization (CEM) somente aos dados originais, isto é, sem levar em consideração as covariáveis $(\mathbf{z})$;

2. CEM-dimension: da mesma forma utilizamos o algoritmo clustering expectation-maximization (CEM), porém considerando as covariáveis como novas dimensões dos dados, conforme discutido na Seção 2.1; e

3. CEM-partial: inicialmente calculamos modelos de regressão linear em que cada dimensão é a variável resposta e as covariáveis são as variáveis explicativas. Depois, utilizamos os resíduos destes modelos de regressão como o novo espaço de agrupamento e aplicamos novamente o algoritmo CEM (Seção 2.2).

O método do three-step approach, descrito anteriormente, tem o mesmo resultado da estrutura dos grupos do CEM, visto que o three-step approach agrupa os dados utilizando o algoritmo CEM e depois identifica as correlações entre os 
grupos formados e as covariáveis utilizando uma regressão logística. Sendo assim, não comparamos o CEM-Co com o three-step approach.

Já o one-step approach não foi utilizado pois estudos recentes ([41], [75], [59]) apresentaram evidências de que os parâmetros obtidos na primeira etapa dos modelos de latent class analysis podem ser afetados por variáveis auxiliares.

Por fim, a implementação de [57] e [58] é um caso particular do CEM-Co, com efeitos lineares apenas nos centroides das distribuições gaussianas. A vantagem desses métodos é a possível parametrizações das matrizes de covariância. No entanto, como nas simulações, utilizamos matrizes de covariâncias sem suposições de independência. Por conta disso, esse método não teria ganhos reais.

\subsection{Métricas}

Para comparar os métodos descritos na Seção 4.2 com o CEM-Co, utilizamos principalmente a métrica conhecida como adjusted rand index, que é baseada em outras duas métricas, o próprio rand index e o Jaccard index.

Tomemos $X$ e $Y$ como duas estruturas de agrupamento. Consideramos que $X$ seja a estrutura de agrupamento "esperada" e $Y$ seja a estrutura de agrupamento obtida utilizando qualquer algoritmo de agrupamento. Assim, para definirmos o Jaccard index [39] e as outras métricas, primeiramente, comparamos todos os $\left(\begin{array}{c}N \\ 2\end{array}\right)$ pares de observações. Para cada par, há quatro possibilidades: (i) ambas as observações estão agrupadas juntas tanto na estrutura de $X$ quanto na estrutura de agrupamento de $Y$; (ii) ambas as observações não são agrupadas juntas nem em $X$ nem em $Y$; (iii) as duas observações são agrupadas juntas em $X$, mas não em $Y$; e (iv) as duas observações não são agrupadas juntas em $X$, mas são agrupadas juntas em $Y$. Sejam $A, B, C$, e $D$ os números de pares de observações que satisfazem as condições (i), (ii), (iii), e (iv), respectivamente. Então, definimos o Jaccard index como:

$$
J=\frac{A}{B+C+D}
$$

O Jaccard index assume valores entre zero e um. Quando $J=0$, as duas estruturas de agrupamento são completamente diferentes. Por outro lado, se $J=1$, então as duas estruturas de agrupamento $X$ e $Y$ são idênticas. Valores 
entre 0 e 1 representam a proporção de pares das observações que são agrupadas juntas tanto em $X$ quanto em $Y$. Logo, Jaccard index próximo de 1 indica boa performance, enquanto que próximo de 0 indica uma baixa performance.

A construção da métrica do Rand index é similar e definada como:

$$
R=\frac{A+B}{A+B+C+D}
$$

Da mesma forma, o Rand index varia entre zero e um, indicando a mesma estrutura de agrupamento quando $R=1$.

Um problema do Rand index é que o valor esperado entre duas estruturas de agrupamento aleatórias não assume um valor constante como, por exemplo, zero. Assim, 37] definiu o Adjusted Rand index, que é definido como:

$$
A R=\frac{R-E}{\max (R)-E},
$$

em que $R$ é o Rand index, $E$ é o valor esperado do $R a n d$ index e $\max (R)$ é o valor máximo do Rand index. Nota-se que tal métrica apresenta o valor zero sob partições aleatórias e é igual a um com duas estruturas de agrupamento equivalentes.

Mais detalhes do Adjusted Rand index podem ser encontrados em [88].

Essas métricas estão implementadas no pacote clusteval do $\mathrm{R}$ dentro da função comembership_table.

\subsection{Resultados}

Primeiramente, analisamos o cenário em que as covariáveis são associadas linearmente apenas com os centroides (cenário 1). Para avaliarmos o quão bem os algoritmos agrupam as observações, utilizamos o Adjusted Rand index para cada uma das 300 repetições das simulações.

É importante comentar que, como simulamos os dados, temos a estrutura de agrupamento real e comparamos com as estruturas de agrupamento obtidas pelos 4 diferentes algoritmos (CEM-Co, CEM, CEM-Dimension e CEM-Partial).

Para cada repetição, calculamos a diferença entre o Adjusted Rand index do CEM-Co e os outros 3 algoritmos (Figura 2A). Quanto maior a diferença, melhor 
é a performance do CEM-Co em relação ao algoritmo competidor. A Figura 2 A apresenta tais resultados, que nos levam à conclusão de que a performance do CEM-Co é melhor do que a de todos os outros algoritmos considerados.

Podemos observar que o CEM-Co apresenta resultados melhores em todos os tamanhos amostrais considerados, alterando apenas o tamanho do intervalo de confiança de $95 \%$ desta diferença (representado pelas linhas). O intervalo de confiança apresentado foi calculado por bootstrap utilizando as 300 réplicas. A barra no gráfico representa a diferença média entre os algoritmos nas réplicas.

Além de avaliarmos a estrutura de agrupamento obtida, também avaliamos se a métrica de BIC (Bayesian Information criteria) proposta para selecionarmos o número de grupos era realmente adequada para o CEM-Co.

A Figura 2B nos apresenta a distribuição de frequência do número de grupos selecionados pelo BIC para as 300 réplicas. Como esperado, o BIC encontrou o número correto de grupos ( $K=2$ neste cenário) para todas amostras realizadas independentemente do tamanho amostral.

Outro teste que realizamos com as simulações foi calcular o poder do teste de razão de verossimilhança para detectar o efeito das covariáveis. Na Figura $2 \mathrm{C}$ apresentamos a curva ROC desse teste. Para verificar o controle do erro do tipo I, simulamos uma base de dados da mesma forma descrita na Seção 4.1- cenário 1, mas sem considerar o efeito das covariáveis (sob a hipótese nula). Podemos observar que quando $\beta=0$ (sem efeito da covariável), a curva ROC (linha sólida) deveria estar na diagonal.

Analisando os resultados, observamos que, para $N=360$, o teste de razão de verossimilhança controla efetivamente o erro do tipo I (a linha sólida está muito próxima à diagonal). Entretanto, para $N=120,240$, as curvas ROC (linhas sólidas) estão acima da diagonal, isto é, rejeitaríamos a hipótese nula mais do que o esperado para um determinado valor de p-valor.

Assim, ao invés de utilizarmos o teste de razão de verossimilhança, propomos a utilização de um bootstrap paramétrico para um tamanho amostral $(N)$ pequeno. O teste consiste em simular repetidamente os dados com os parâmetros obtidos pelo ajuste do CEM-Co sem a presença do efeito da covariável e assim obter uma distribuição de valores estimados deste efeito, verificando como o valor estimado está posicionado nessa distribuição. 
Para $N=120$ e analisando os pontos de corte de p-valores de 0.01,0.05, e 0.10, a distribuição de falsos positivos para o teste empírico de bootstrap (com 1000 amostras de bootstrap) foi 0.01,0.07, e 0.16, respectivamente, enquanto que no teste de razão de verossimilhança foi de 0.06,0.17, e 0.27. Conclui-se que, para um amostral tão pequeno, o erro do tipo I é melhor controlado pelo teste de bootstrap.

Já sob a hipótese alternativa (efeito das covariáveis), a proporção de rejeição (poder do teste) do teste de razão de verossimilhança aumenta com o número de observações $(N)$ e/ou o efeito das covariáveis aumenta (linhas pontilhadas), em linha com o esperado.

Aplicamos as mesmas métricas para o cenário 2, isto é, em que temos efeitos das covariáveis tanto nos centroides quanto nas matrizes de covariâncias. Vale lembrar que, neste cenário, simulamos mais grupos $(K=4)$ e menos covariáveis.

A Figura 34A nos mostra as diferenças do adjusted rand index do CEM-Co em relação aos demais métodos. Podemos ver que, mais uma vez, o CEM-Co se mostra melhor para todos os tamanhos amostrais considerados. Mais uma vez, podemos ver que o aumento do tamanho amostral diminui o intervalo de confiança da diferença.

Já a Figura $3 \mathrm{~B}$ nos mostra que, para tamanhos amostrais pequenos, o BIC não consegue estimar corretamente o número de grupos como sendo igual a 4 . Nota-se que para $N=200,2$ grupos é a opção mais escolhida, seguida de perto por 3 grupos. No entanto, na medida em que aumentamos o número de observações, percebemos uma clara melhora na escolha do BIC. Com $N$ igual a 800, percebemos que em quase todas as simulações são escolhidos 4 grupos.

Por fim, a Figura 3C nos mostra que, sob a hipótese nula, o teste de razão de verossimilhança proposto efetivamente controla o erro do tipo I (linhas sólidas estão bem próximas da diagonal) para todos os tamanhos de amostra considerados. Já para a hipótese alternativa (efeito das covariáveis), a proporção de rejeição do teste (poder do teste) pelo teste de razão de verossimilhança aumenta com o número de observações, além de aumentar o efeito das covariáveis (linhas pontilhadas).

Vale ressaltar que o teste do efeito das covariáveis foi realizado tanto para o efeito no centroide quanto para o efeito na matriz de covariância. No entanto, o 


\section{(A)}
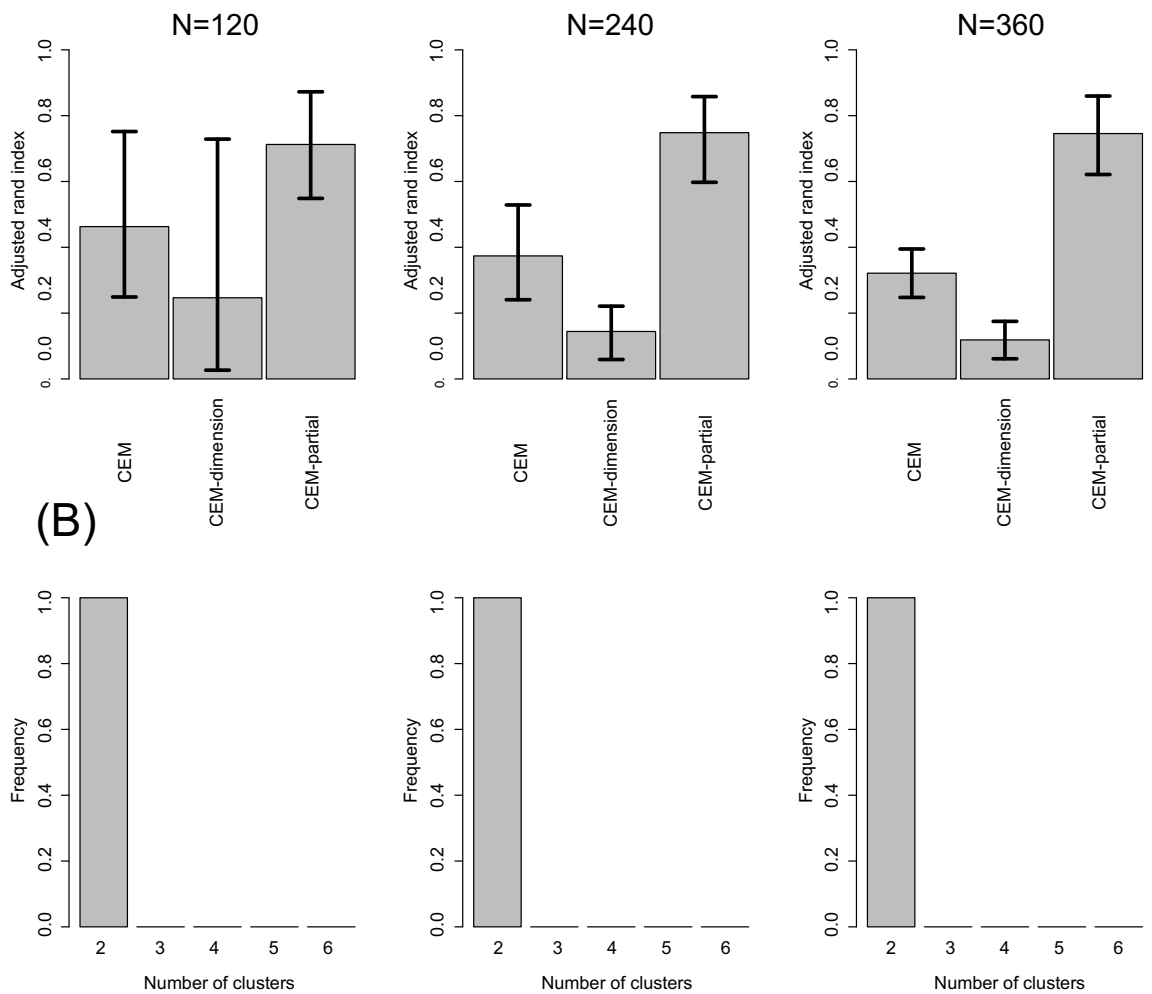

(C)
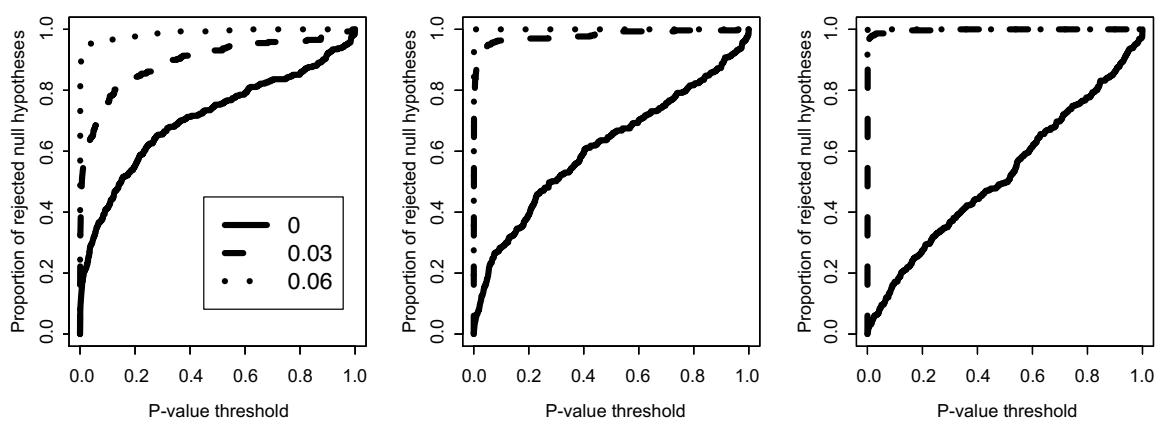

Figura 2: Efeitos lineares das covariáveis nos centroides. (A) Diferenças entre adjusted rand indexes obtidos pelo CEM-Co e os métodos alternativos (CEM, CEM-dimension e CEM-partial). Quanto maior a diferença, melhor é a performance do CEM-Co. As barras de erro representam intervalos de confiança de 90\%. (B) Estimação do número de grupos. As barras representam a distribuição de frequência do número de grupos selecionados pelo critério de BIC. Para todos os tamanhos amostrais considerados, BIC selecionou 2 grupos. (C) Curvas ROC. A área abaixo da curva representa o poder do teste estatístico. A linha sólida representa efeito da covariáveis sob a hipótese nula $(\beta=0)$. Linhas pontilhadas representam o teste sob a hipótese alternativa $(\beta>0)$. O poder do teste de razão de verossimilhança aumenta com o número de observações $(N)$ e a força do efeito da covariável. Para tamanhos amostrais pequeno $(N=120,240)$, o teste não controlou o erro do tipo I. 
teste de razão de verossimilhança é flexível o bastante para testarmos apenas o efeito no centroide ou apenas na matriz de covariância.

As mesmas análises foram realizadas para as simulações do cenário 3 , em que o efeito das covariáveis nos centroides é não linear. Neste caso, todas as estimativas do CEM-CO foram geradas com uso das bases do $B$-splines.

A Figura 4A nos apresenta os resultados das diferenças do adjusted rand index entre o CEM-Co e os método concorrentes, indicando uma alta superioridade do CEM-Co, independentemente do tamanho amostral. Apenas os intervalos de confiança se tornam mais estreitos quando aumentamos o número de observações considerados na amostra.

Já a Figura 4B indica que o número correto de grupos $(K=4)$ foi selecionado em todas as réplicas consideradas, independentemente do número de observações.

Por fim, a Figura $4 \mathrm{C}$ nos indica que sob a hipótese nula, o teste de razão de verossimilhança, novamente, controla o erro do tipo I, visto que as linhas sólidas convergem para a diagonal, com tamanho amostral maior do que 400. Um cuidado extra deve ser tomado em situações com tamanho amostral menor, e o teste utilizando o bootstrap deve ser indicado. Sob a hipótese alternativa, a proporção de rejeição (poder do teste de razão de verossimilhança) aumenta com o número de observações $(N)$ e com a força do efeito das covariáveis (linhas pontilhadas). Esse é o mesmo comportamento para os cenários anteriores e mostra a eficácia do método.

\subsection{Convergência das estimativas}

Para avaliarmos a convergência das estimativas para seus valores, utilizamos novos cenários de simulação, supondo menos covariáveis para facilitar a visualização dos resultados.

Os cenários 2 e 3 não foram alterados. No entanto, o cenário 1 foi alterado para:

Cenário 1 - convergência: efeito linear das covariáveis nos centroides dos grupos. 
(A)
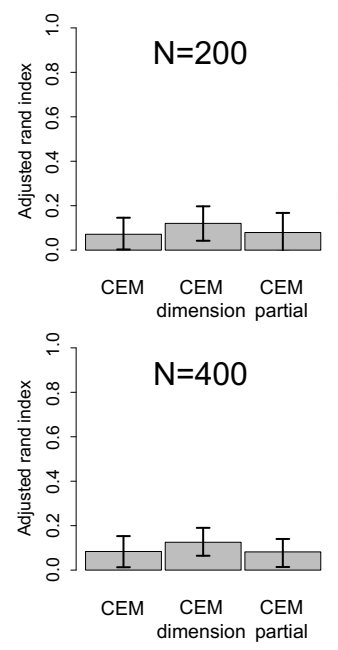
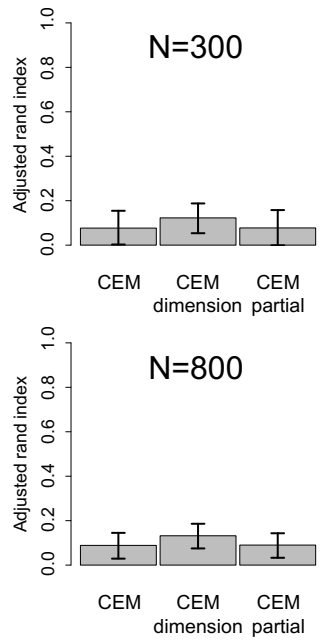

(B)
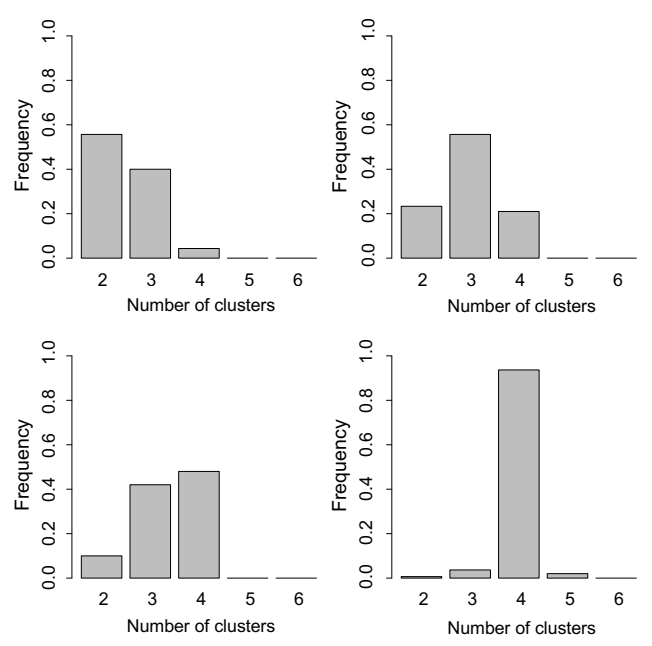

\section{(C)}
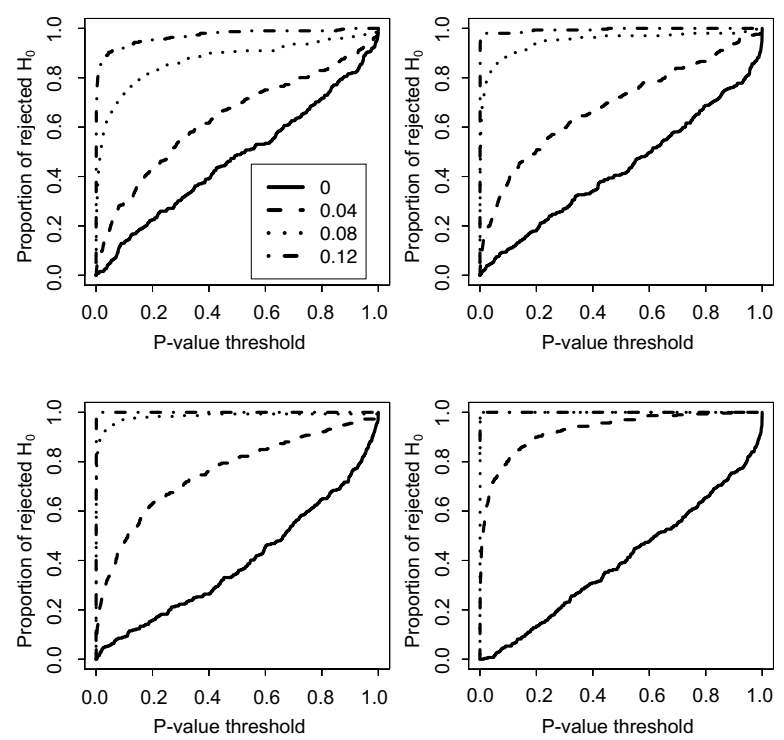

Figura 3: Efeitos lineares das covariáveis tanto nos centroides quanto nas matrizes de covariância. (A) Diferenças entre o adjusted rand indexes obtidos pelo CEM-Co e os métodos alternativos (CEM, CEM-dimension e CEM-partial). Barras de erro de 90\% (B) Estimação do número de grupos. As barras representam a distribuição de frequência do número de grupos selecionados pelo critério de BIC. (C) Curvas ROC. A área abaixo da curva representa o poder do teste estatístico. A linha sólida representa efeito das covariáveis sob a hipótese nula $(\beta=0)$. Linhas pontilhadas representam o teste sob a hipótese alternativa $(\beta>0)$. 
(A)
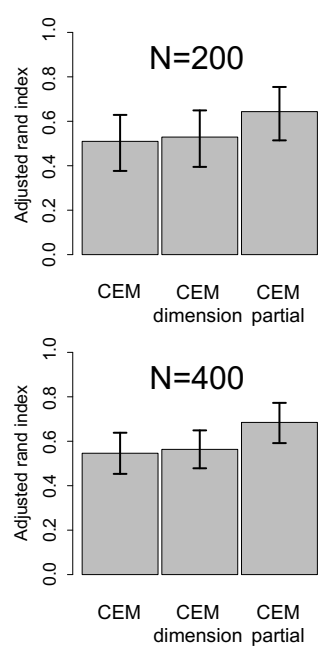
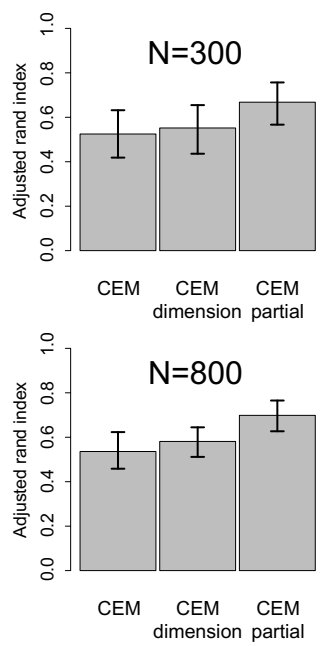

(B)
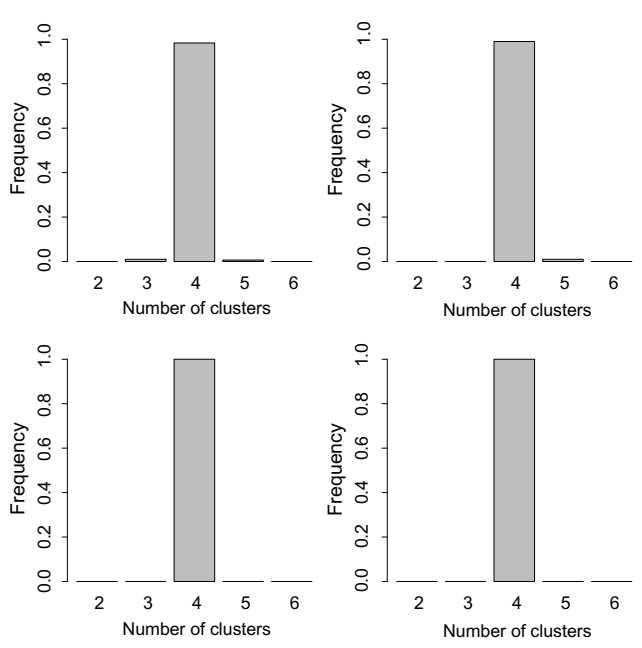

(C)
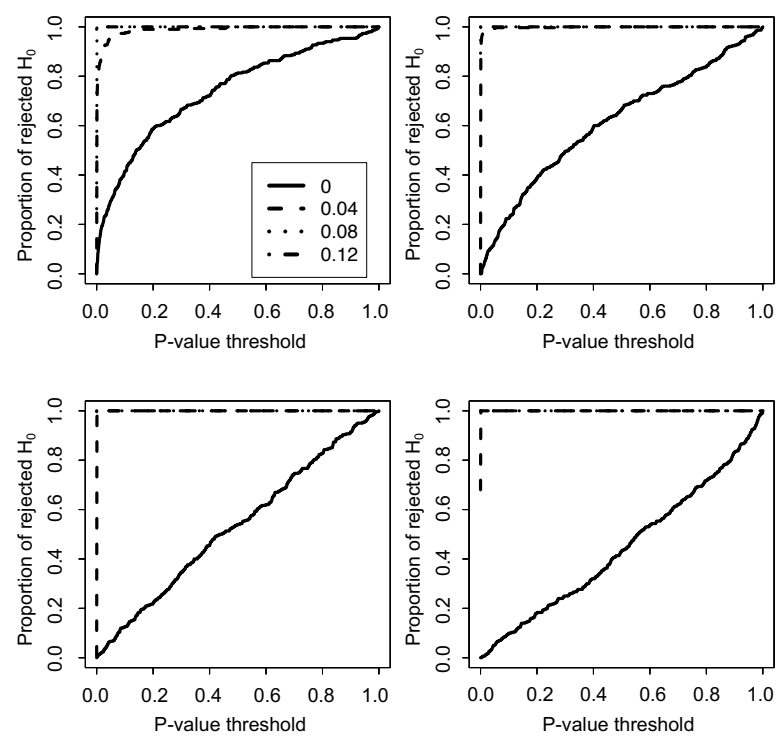

Figura 4: Efeito não linear nos centroides dos grupos. (A) Diferenças entre o adjusted rand indexes obtidos pelo CEM-Co e os métodos alternativos (CEM, CEM-dimension e CEM-partial). Barras de erro de 90\% (B) Estimação do número de grupos. As barras representam a distribuição de frequência do número de grupos selecionados pelo critério de BIC. (C) Curvas ROC. A área abaixo da curva representa o poder do teste estatístico. A linha sólida representa efeito das covariáveis sob a hipótese nula $(\beta=0)$. Linhas pontilhadas representam o teste sob a hipótese alternativa $(\beta>0)$. 
1. Escolhemos o número de grupos igual a $4(K=4)$, a dimensão dos dados igual a $2(M=2)$, e apenas uma covariável $(P=1)$.

2. Fixamos os centroides (médias) dos grupos $(K=4)$ iguais a $\mu_{1}^{*}=(0,0)$, $\mu_{2}^{*}=(0,1), \mu_{3}^{*}=(1,0)$ e $\mu_{4}^{*}=(1,1)$.

3. Os efeitos das covariáveis em cada grupo $(\beta)$ foram escolhidos como $\beta_{1}=$ $(0.3,0.3), \beta_{2}=(-0.3,-0.3), \beta_{3}=(0.3,-0.3)$, e $\beta_{4}(-0.3,0.3)$.

4. Simulamos a covariável a partir de uma distribuição normal com média 1 e variância igual a um $\left(\mathbf{z}_{1, i} \sim N(1,1)\right)$.

5. Por fim, simulamos $N / 4$ observações para cada grupo a partir de uma distribuição gaussiana multivariada com médias iguais a $\mu_{i, j}=\mu_{j}^{*}+\beta_{j} \mathbf{z}_{1, i}$ (para $i=1, \ldots, N / 4$ e $j=1,2,3,4$ ) e com matriz de covariância igual a uma matriz identidade $(2 \times 2)$ multiplicada por 0.1 para cada grupo.

Para esses 3 novos cenários, o número de observações simuladas variaram em $N=200,300,400$, e 800. Para o cenário 3, novamente modelamos a função $f_{j, 1}$ com $B$-spline cúbico com quatro graus de liberdade. Também repetimos os experimentos 300 vezes (300 réplicas) para verificarmos as propriedades de convergência do CEM-Co.

Os resultados de performance (adjusted rand index), da efetividade do BIC para a escolha do número de grupos e do poder de teste de razão de verossimilhança para este novo cenário 1 ficaram muito próximos aos resultados obtidos anteriormente, conforme Figura 2 .

Já analisando a convergência das estimativas para seus verdadeiros valores simulados tanto para $\mu_{j}$ e $\beta_{j}, j=1,2,3$ e 4 na Figura 5, notamos que para os cenários 1 (efeito linear apenas nos centroides) e 2 (efeito linear tanto nos centroides quanto nas matrizes de covariância), os valores médios das estimativas estão muito próximos dos valores reais. Além disso, os intervalos de confiança 


\section{Scenario 1}
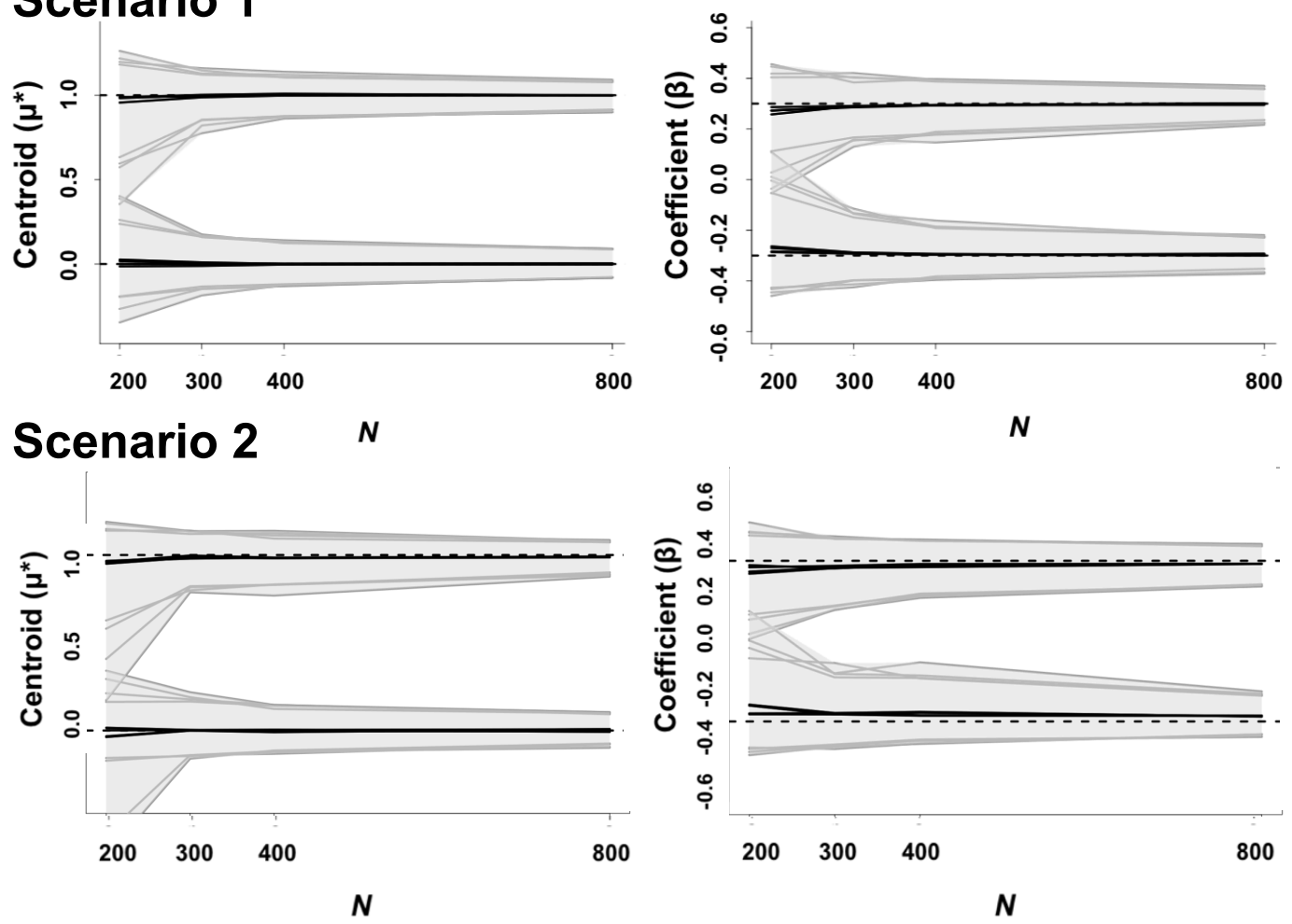

Figura 5: Convergência das estimativas para os parâmetros $\mu_{j}$ e $\beta_{j}, j=1,2,3$ e 4 . Linhas pretas representam o valor médio das estimativas das 300 réplicas, enquanto que as linhas cinzas representam o intervalo de confiança de $95 \%$ de bootstrap das estimativas para os tamanhos amostrais considerados $(N=200,300,400$ e 800$)$ e para os cenários 1 (efeito linear apenas nos centroides) e 2 (efeito linear tanto nos centroides quanto nas matrizes de covariâncias). Como temos $K=4$ grupos, temos 4 linhas por volta do parâmetro simulado, bem como 0 e 4 linhas por volta do parâmetro simulado como 1 para $\mu_{j}$ e $\beta_{j}$.
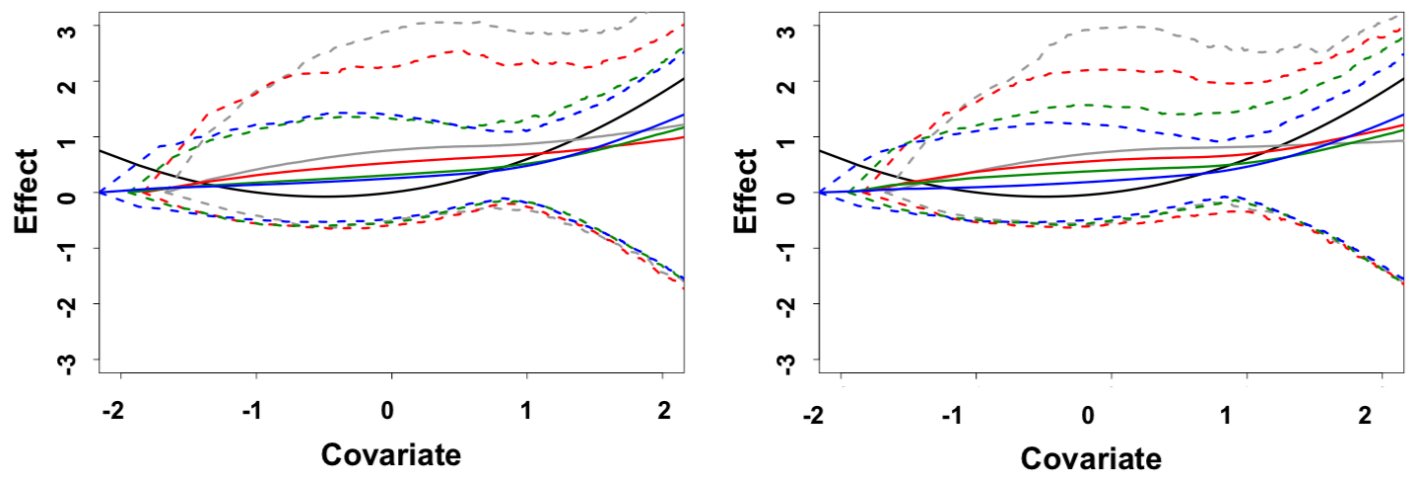

Figura 6: Convergência das estimativas da função quadrática para o primeiro grupo (figura esquerda) e para o segundo grupo (figura da direita). Linhas pretas representam o valor da função quadrática utilizada nas simulações. Linhas sólidas representam a função quadrática média estimada nas 300 réplicas enquanto que linhas pontilhadas representam o intervalo de confiança de bootstrap de $95 \%$ das curvas estimadas. Linhas cinzas são para $N=200$, vermelhas são para $N=300$, verdes para $N=400$ e azuis para $N=800$. 
estreitam-se rapidamente. Assim, podemos observar que com $N=800$ os intervalos de confiança são bem pequenos e próximos do valor real. Apenas para o cenário 2 , percebemos um pequeno viés para $\beta_{j}, j=1,2,3$ e 4 , que diminui conforme aumentamos o tamanho amostral.

Por fim, para o cenário 3 com efeito não linear nos centroides, percebemos ao analisar a Figura 6 que a curva utilizada na simulação (em preto) está sempre dentro dos intervalos de confiança estimados para os quatro tamanhos amostrais e os dois grupos considerados. No entanto, a forma da curva parece não ser capturada corretamente, a não ser para os tamanhos amostrais maiores em que a curva estimada se torna mais próxima. Isso pode indicar a necessidade de um maior tamanho amostral para situações em que o efeito é não linear.

\subsection{Conclusões}

Com as simulações presentes neste Capítulo, podemos perceber a eficiência do CEM-Co em controlar o efeito das covariáveis, lineares ou não lineares, nos centroides e nas matrizes de covariância. Além de obter uma estrutura de agrupamento significativamente melhor do que os concorrentes nos diferentes cenários.

Também pudemos verificar o comportamento do critério BIC para a escolha do número de grupos, apontando as situações em que este critério se mostrou adequado (tamanho amostral).

Além disso, foi possível identificar cenários nos quais o teste de razão de verossimilhança proposto não se mostrou adequado para controlar o erro do tipo I. No entanto, nessas situações, indicamos o uso de um teste empírico utilizando bootstrap, que apresentou resultados superiores. 


\section{Aplicação Prática}

\section{Aplicação Prática}

Neste Capítulo apresentamos uma aplicação real do CEM-Co em uma base de dados de câncer de pulmão. Nesta aplicação foi possível identificarmos grupos de pacientes com sobrevida diferente controlando por algumas covariáveis, o que não teria sido possível utilizando métodos de agrupamento tradicionais ou os outros métodos comparados no Capítulo 4.

Estes resultados indicam que, para um determinado subgrupo dos pacientes considerados, há espaço para melhorias nos atuais tratamentos ou criação de novos procedimentos para aumentar a sobrevida dessas pessoas.

\subsection{Problema}

Câncer de pulmão é um dos tipos de câncer mais mortais em todo o mundo. Em 2019, apenas nos Estados Unidos, foram estimados 228.150 novos casos e 142.670 mortes (American Cancer Society). Existem dois tipos principais de câncer de pulmão: câncer de pulmão de células não pequenas (NSCLC do inglês) e câncer de pulmão de células pequenas (SCLC). Estes tipos são aproximadamente 80\% e cerca de 10 a $15 \%$ dos cânceres de pulmão, respectivamente.

Entre os pacientes com estágio do tipo NSCLC, é estimado que cerca de $30 \%$ a $40 \%$ apresentam alguma recaída, sendo que $10 \%$ a $30 \%$ morrem devido à recorrência. Estas estatísticas sugerem a presença de pelo menos um subgrupo que poderia se beneficiar de novas terapias, quando identificado apropriadamente. Assim, maiores estratificações e identificações desses pacientes se fazem necessárias.

Umas das hipóteses levantadas é que a falha de identificar corretamente estes pacientes com estágio I de NSCLC se deve a efeitos de covariáveis. Por exemplo: é conhecido que idade no diagnóstico (e muitas outras covariáveis) está associada com a doença. Portanto, nosso principal problema é remover/minimizar os 
efeitos de covariáveis clínico-patológicas não desejáveis (como idade, gênero, terapias complementares e diferenciação) que podem mascarar os resultados obtidos durante a estratificação do estágio I de NSCLC.

\subsection{Dados de estágio I de NSCLC}

Os dados foram coletados de um conjunto de dados de expressão gênica, anotados clinicamente e compostos por 45 genes (ADAM10, ADAM19, ADAM8, ALOX15B, ATF2, CENPF, CXCL1, ETS2, FOSL1, GAD1, GAPDH, GNG4, GNG11, GRB10, HMGA2, HOPX, HSPA8, ID1, IGFBP3, IGFBP6, IL1A, IL1RN, ITGB8, ITPR1, MMP12, MTHFD2, MVK, NDRG1, PAK2, PHLDA2, PIK3CD, RAC2, S100A2, SEPW1, SERPINB5, SMOX, SPDEF, SPRY 4, THRA, TMSB10, UBE2C, UST, VCP, VEGFA, and YWHAQ), bem como 129 pacientes com estágio I da NSCLC, por RT-PCR em tempo real com matrizes personalizadas de baixa densidade TaqMan (cartões micro fluídicos de 384 poços) (Applied Biosystems). Todos os procedimentos foram realizados de acordo com protocolo do fabricante. Normalizamos os níveis das expressões gênicas em relação ao gene $18 \mathrm{~S}$ de controle interno de limpeza, usando o método descrito em [67].

Algumas características clínicas e patológicas estão descritas na Tabela 1. O Conselho de Revisão Institucional da Universidade de Michigan aprovou o uso desses dados e deste estudo.

Nós redimensionamos os dados de expressão gênica para média zero e variância um. Então, aplicamos o método de componentes principais (PCA) para redução da dimensão dos dados, visto que o ajuste do CEM-Co com dados de dimensão 45 não seria viável pelo número de parâmetros associados. Selecionamos, pelo método de Elbow, cinco componentes principais associados com aos 5 maiores autovalores, que representavam $51,87 \%$ da variância. Na Figura 7 podemos ver o percentual que cada componente explica da variância total. Podemos tambéem observar que, após 5 componentes, a porcentagem da variância explicada decai bastante. Estes 5 componentes principais representam as novas dimensões dos pacientes com estágio I do NSCLC.

Sendo assim, temos $N=129$ pacientes, $M=5$ dimensões, e $P=4$ covariáveis (idade no diagnóstico, gênero, terapia, e diferenciação). 


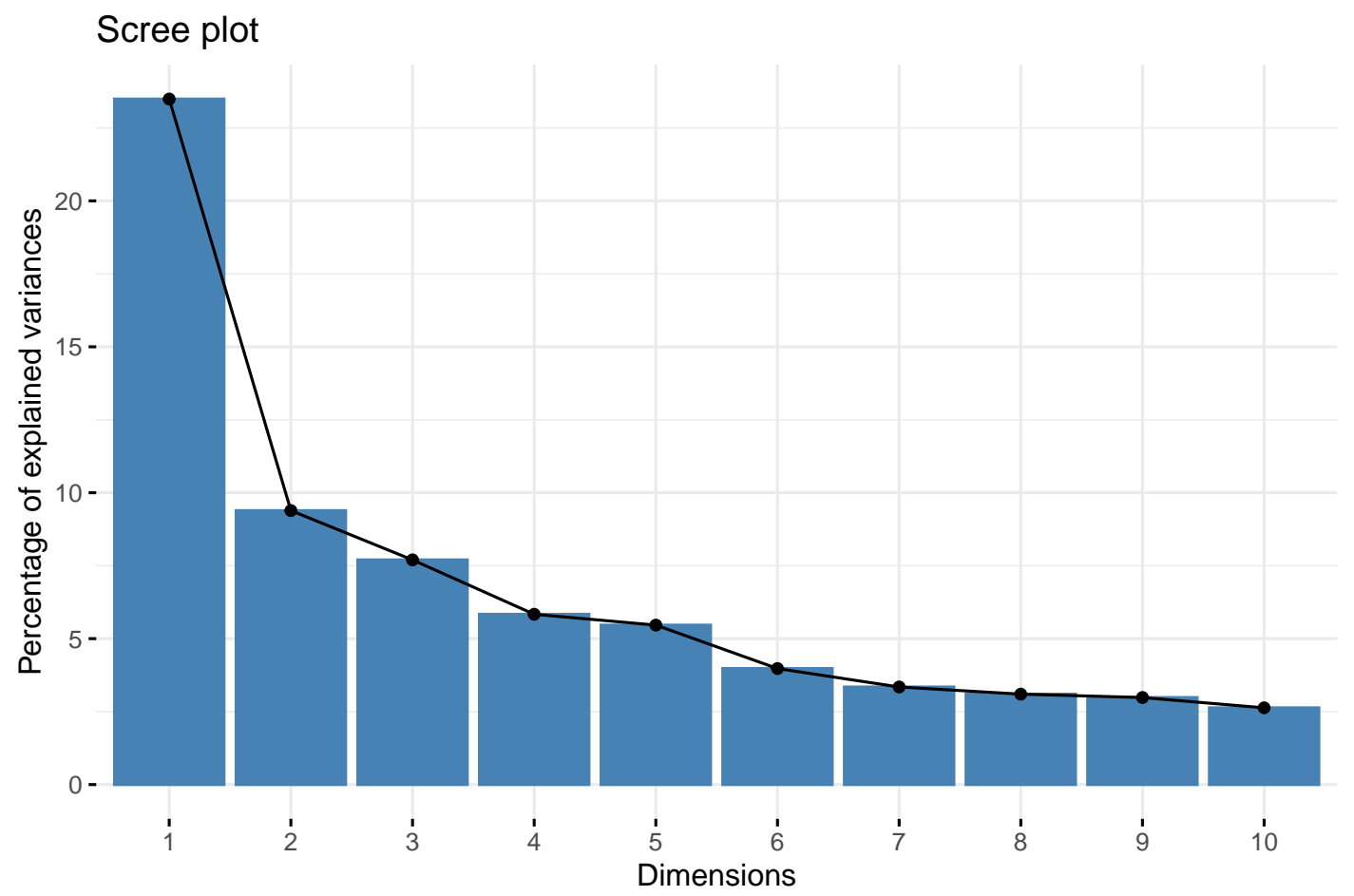

Figura 7: Porcentagem da variância explicada variando o número dos componentes principais aplicados na base de dados de câncer. 
Tabela 1: Características clínicas e patológicas dos pacientes e seus tumores. Os dados são números (\%), exceto quando dito o contrário. SD: desvio padrão.

\begin{tabular}{ccc}
\hline \hline Variável & Status & $n$ \\
\hline \multirow{3}{*}{ Idade no diagnóstico (anos) } & Média (SD) & $66.26(10.04)$ \\
& 655 & $60(46.51)$ \\
Gênero & $69(53.49)$ \\
& Masculino & $59(45.74)$ \\
& Feminino & $74(54.26)$ \\
Terapia & Sim & $18(13.95)$ \\
& Não & $110(85.27)$ \\
& Desconhecido & $1(0.77)$ \\
Diferenciação & 1 & $40(31.00)$ \\
& 2 & $51(39.53)$ \\
& 3 & $38(29.46)$ \\
Morto & Sim & $48(37.21)$ \\
& Não & $81(62.79)$ \\
\hline
\end{tabular}

Vale ressaltar que todo o procedimento desta aplicação real foi repetido utilizando 4 e 6 componentes principais sem grandes alterações nos resultados, indicando robustez das conclusões encontradas.

Assim como nas simulações apresentadas no Capítulo 4, aplicamos os outros três métodos (CEM, CEM-dimension e CEM-partial) nos dados de expressão gênica de NSCLC estágio I.

Para este cenário real, aplicamos o CEM-Co com efeitos lineares apenas nos centroides. Não investigamos possíveis efeitos das covariáveis na matriz de covariância nem efeitos não lineares nos centroides visto que o número de parâmetros aumentaria consideravelmente e tínhamos um número limitado de pacientes $(N=129)$.

Para estimar o número de grupos a ser utilizado na análise, aplicamos o critério de BIC descrito na Seção 3.4. Para todos algoritmos de agrupamento, o número estimado de grupos foi igual a dois. A justificativa para a escolha de 2 


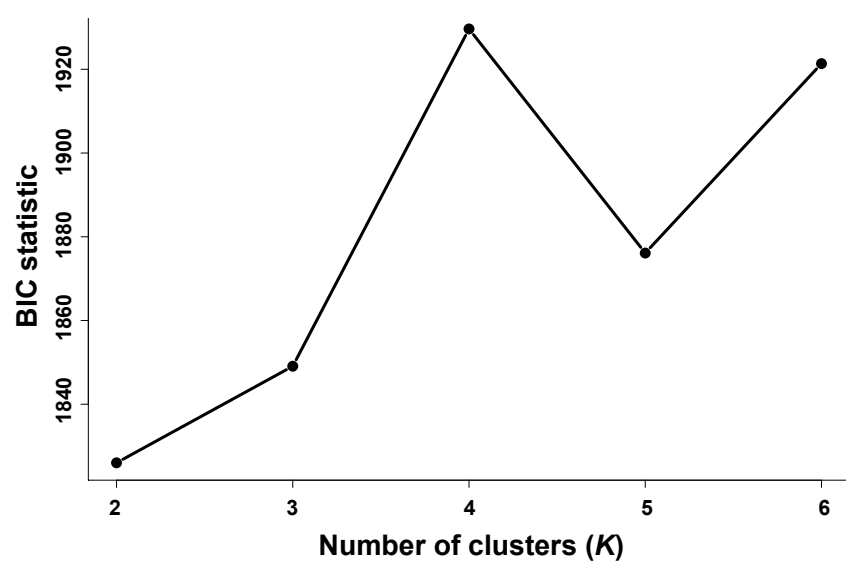

Figura 8: Critério de BIC para a estimação do número de grupos dos dados de expressão gênica do NSCLC do estágio 1 para o algoritmo CEM-Co. Podemos ver que a estatística BIC alcança o valor mínimo para $K=2$. Portanto, o número estimado de grupos para este conjunto de dados é $\hat{K}=2$.

grupos pode ser vista na Figura 8, Nota-se que 3 grupos também poderia ser uma escolha plausível, dada a proximidade do critério de BIC entre 2 e 3 grupos. Por conta disso, também executamos a análise com 3 grupos sem grandes alterações nas conclusões.

Utilizamos as covariáveis idade no diagnóstico, gênero, terapia auxiliar e diferenciação para o ajuste do CEM-Co.

Após agruparmos os pacientes em dois grupos utilizando os algoritmos CEMCo, CEM, CEM-dimension e CEM-partial, verificamos se os grupos encontrados apresentavam diferentes fenótipos. Obviamente, o tempo de sobrevida dos pacientes com câncer é de extrema importância. Portanto, analisamos os tempos de sobrevida dos dois grupos encontrados (para cada algoritmo estimado) utilizando curvas não-paramétricas de Kaplan-Meier, que podem ser vistas na Figura 9.

Analisando a Figura 9, podemos observar que, dentre todos os algoritmos, o CEM-Co é aquele que apresenta dois grupos com maior diferença na taxa de sobrevida. Podemos ver isso analisando os p-valores, mas tal diferença também é visualmente perceptível. No entanto, o resultados dos quatro algoritmos apresentam p-valores menores do que 0.10 .

As curvas de sobrevivência de Kaplan-Meier não levam em consideração possíveis efeitos de covariáveis, utilizando apenas os dois grupos encontrados. 

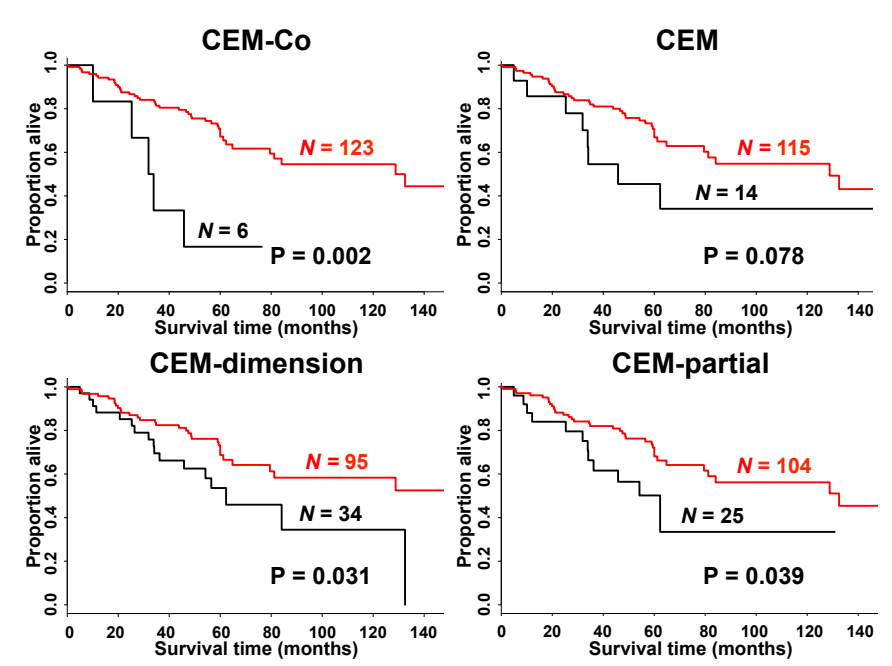

Figura 9: Curvas de sobrevivência de Kaplan-Meier construídas com base nos grupos obtidos pelas aplicações de CEM-Co, CEM, CEM-dimension e CEM-partial, nos dados de expressão gênica dos pacientes com estágio I de NSCLC. Os p-valores foram obtidos com a aplicação do teste de log-rank.

Para podermos controlar esses efeitos, aplicamos os modelos de riscos proporcionais de Cox multivariado utilizando as mesmas covariáveis aplicadas ao CEM-Co (idade, gênero, terapia auxiliar e diferenciação).

Os resultados dos modelos de Cox para os grupos obtidos pelos quatro algoritmos podem ser encontrados na Tabela 2).

Utilizando o critério usual de p-valor de $5 \%$ na análise de Kaplan-Meier (KM), apenas o algoritmo CEM não estratificou os dados de expressão gênica do estágio I de NSCLC em dois grupos com diferentes tempos de sobrevida (Figura 9). No entanto, como falamos anteriormente, a análise de Kaplan-Meier não remove efeitos das covariáveis. Já analisando os resultados do modelo de regressão de Cox, que controla efeitos das covariáveis, percebemos que apenas os grupos identificados com o algoritmo CEM-Co apresentam curva de sobrevida diferentes estatisticamente significante $(p<0.001)$ (Tabela 2).

A razão do motivo de apenas o CEM-Co ter sido capaz de identificar um subgrupo dos pacientes com estágio I de NSCLC com sobrevida significativamente menor pode ser explicado pelo uso dos efeitos das covariáveis na estrutura de agrupamento.

Como percebemos nos resultados das simulações que, para tamanhos amostrais pequenos (da mesma grandeza desta aplicação), o teste de razão de verossi- 
Tabela 2: Modelos de sobrevivência de riscos proporcionais de Cox multivariado foram estimados com base nos grupos obtidos pelos quatro algoritmos, além das covariáveis. CI: intervalo de confiança. P-valores $<0.05$ estão em negrito.

\begin{tabular}{cccc}
\hline \hline Algoritmo & Variáveis & Razão de risco (95\%CI) & P-valor \\
\hline \multirow{4}{*}{ CEM-Co } & Grupo (Vermelho/Preto) & $0.117(0.041-0.334)$ & $<\mathbf{0 . 0 0 1}$ \\
& Idade no diagnóstico & $1.084(1.048-1.121)$ & $<\mathbf{0 . 0 0 1}$ \\
& Gênero (masculino/feminino) & $1.231(0.668-2.268)$ & 0.5045 \\
& Terapia (sim/não) & $2.545(1.223-5.296)$ & $\mathbf{0 . 0 1 3}$ \\
& Diferenciação $(2 / 1)$ & $1.348(0.605-3.003)$ & 0.466 \\
& Diferenciação $(3 / 1)$ & $2.015(0.853-4.762)$ & 0.1101 \\
\hline & Grupo (Vermelho/Preto) & $0.436(0.181-1.052)$ & 0.0646 \\
CEM & Idade no diagnóstico & $1.082(1.045-1.120)$ & $<\mathbf{0 . 0 0 1}$ \\
& Gênero (masculino/feminino) & $1.220(0.667-2.232)$ & 0.519 \\
& Terapia (sim/não) & $2.151(1.049-4.410)$ & $\mathbf{0 . 0 3 7}$ \\
& Diferenciação $(2 / 1)$ & $2.064(0.701-3.438)$ & 0.278 \\
& Diferenciação (3/1) & $2.064(0.861-4.949)$ & 0.104 \\
\hline Grupo (Vermelho/Preto) & $0.599(0.251-1.429)$ & 0.248 \\
CEM-Dimension & Age at diagnosis & $1.077(1.041-1.115)$ & $<\mathbf{0 . 0 0 1}$ \\
& Gênero (masculino/feminino) & $0.201(0.671-2.228)$ & 0.511 \\
& Terapia (sim/não) & $1.378(0.491-3.871)$ & 0.543 \\
& Diferenciação $(2 / 1)$ & $1.645(0.722-3.750)$ & 0.236 \\
& Diferenciação (3/1) & $2.545(1.108-5.846)$ & $\mathbf{0 . 0 2 8}$ \\
\hline Grupo (Vermelho/Preto) & $0.574(0.290-1.137)$ & 0.111 \\
Idade no diagnóstico & $1.076(1.040-1.114)$ & $<\mathbf{0 . 0 0 1}$ \\
& Gênero (masculino/feminino) & $0.796(0.691-2.284)$ & 0.459 \\
& Terapia (sim/não) & $2.013(0.975-4.156)$ & 0.058 \\
& Diferenciação (2/1) & $1.651(0.737-3.696)$ & 0.223 \\
& Diferenciação (3/1) & $2.538(1.102-5.841)$ & $\mathbf{0 . 0 2 9}$ \\
\hline & & &
\end{tabular}


milhança não controla a taxa de falsos positivos sob a hipótese nula, optamos por usar o procedimento de bootstrap com 1000 réplicas para verificar se os efeitos de cada covariável eram significativos.

Aplicando o teste de bootstrap, percebemos que, com exceção da covariável terapia $(p=0.219)$, todas as outras afetam os centroides dos grupos significativamente. Idade no diagnóstico apresentou p-valor de 0.002, gênero apresentou 0.001 e diferenciação 0.007 .

Os resultados do teste confirmam nossa hipótese de que as covariáveis realmente afetam a estratificação dos pacientes com estágio I de NSCLC.

Vale ressaltar também que os efeitos das covariáveis são diferentes para os centroides dos grupos. Podemos ver na Figura 10 a estimativa dos efeitos de cada covariável para cada grupo. Esse comportamento diferente entre os grupos explica a superioridade do CEM-Co em relação ao CEM-dimension e o CEMpartial, pois estes assumem que as covariáveis afetam igualmente os centroides dos grupos.

Para verificar a robustez dos resultados encontrados, conforme discutimos anteriormente, repetimos todas as análises considerando três grupos $(K=3)$, visto que seria uma boa escolha (Figura 8). Com esta suposição, o grupo maior (melhor prognóstico, curva vermelha na Figura 9) foi dividido em dois grupos (por todos os métodos de agrupamento). Aplicando o modelo de sobrevivência de Cox nestas estruturas de agrupamento, temos para o CEM-Co que o grupo menor continua significativamente com sobrevida pior do que os outros dois, que não apresentaram diferenças significativas entre si. Para os outros grupos obtidos pelos algoritmos CEM, CEM-dimension, e CEM-partial, não foi possível, mais uma vez, encontrar diferenças significativas nas curvas de sobrevida entre os grupos. Sendo assim, as conclusões encontradas com três grupos $(K=3)$ foram as mesmas encontradas com dois grupos $(K=2)$.

Com o intuito de, mais uma vez, verificar a robustez dos resultados encontrados, alteramos a escolha de cinco componentes principais $(M=5)$ para quatro $(M=4)$ e seis $(M=6)$. Com quatro componentes $(46.41 \%$ da variância total explicada), os resultados foram praticamente os mesmos, mas quando consideramos seis componentes (representando $55.8 \%$ da variância total), o critério de BIC nos indica a utilização de três grupos. No entanto, percebemos, mais uma 
Age at diagnosis
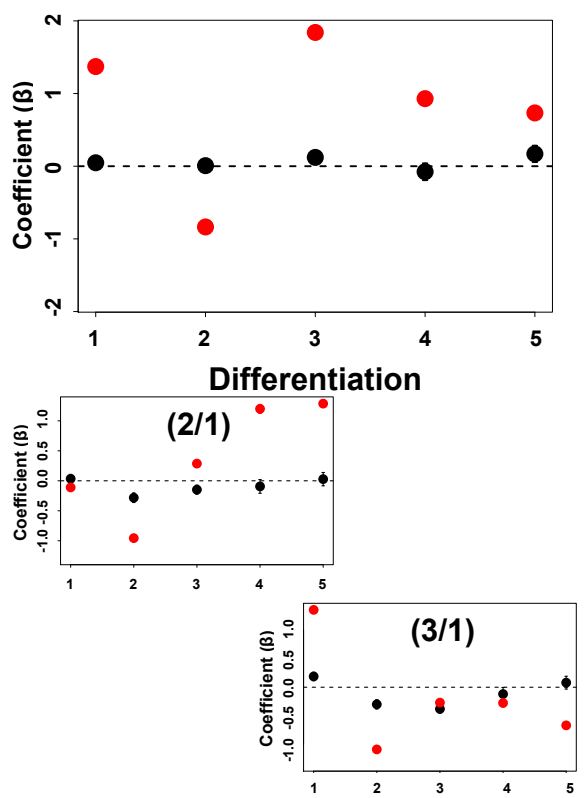

Gender (male/female)
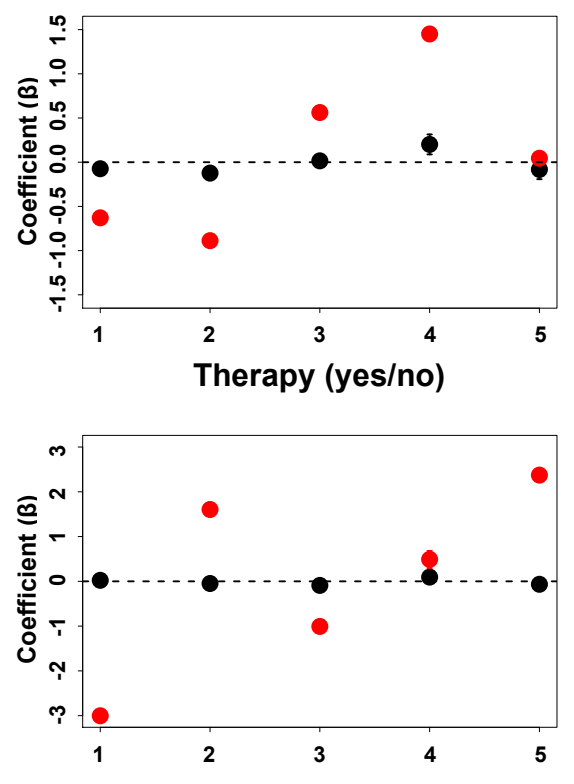

Figura 10: Efeitos estimados das covariáveis utilizando o algoritmo CEM-Co nos dados de estágio I dos paciente com NSCLC. Os eixos $x$ e $y$ representam as $M=5$ dimensões das observações (componentes principais) e os coeficientes $(\beta)$ para cada efeito das covariáveis. Os pontos pretos e vermelhos representam os pacientes com mau e bom prognóstico, respectivamente. As barras de erro representam intervalos de confiança de $95 \%$ (alguns não podem ser vistos por serem muito pequenos). Com exceção da terapia $(p=0.219)$, todas as outras covariáveis são significativamente associadas aos centroides dos grupos (idade no diagnóstico $-p=0.002$, gênero - $p=0.001$, e diferenciação - $p=0.007$ ). Nota-se que os coeficientes (efeitos das covariáveis) varia entre os grupos (pontos vermelhos e pretos) e as cinco dimensões. Os coeficientes próximos do zero com prognóstico pior (pontos pretos) podem possivelmente ser explicados pelo tamanho amostral muito pequeno neste grupo. 
vez, que apenas o grupo maior foi dividido em dois grupos, e temos que o grupo menor continua com uma curva de sobrevida estatisticamente pior do que os outros dois grupos, que permanecem sem diferenças entre si.

Com estas análises de robustez, percebemos que os resultados apresentados se mantêm, mesmo alterando-se o número de grupos utilizados ou o número de componentes principais escolhidos.

Os resultados apresentados neste Capítulo nos mostram a importância e efetividade do algoritmo CEM-Co em estratificar os dados do estágio I de NSCLC por minimizar os efeitos das covariáveis idade no diagnóstico, gênero, terapia auxiliar e diferenciação.

Assim, imaginamos que a flexibilidade que o CEM-Co apresenta pode tornálo muito útil em diferentes aplicações e áreas em que a análise de agrupamento é importante. Bom exemplo disso seriam projetos de grandes imagens neurais, nos quais é conhecido que o local em que os dados são coletados impacta consideravelmente os resultados. 


\section{Conclusões e Próximos Passos}

\section{Conclusões e Próximos Passos}

Neste último Capítulo apresentamos as conclusões do trabalho na Seção6.1, além de discutirmos possíveis próximos passos, na Seção 6.2, que acreditamos ser de interesse para aumentar a usabilidade prática do CEM-Co.

\subsection{Conclusões}

Neste trabalho, apresentamos o algoritmo de agrupamento CEM-Co, que generaliza o algoritmo de agrupamento CEM para a possível presença de efeitos de covariáveis. A grande contribuição é a possibilidade de controlar efeitos lineares das covariáveis tanto nos centroides quanto nas matrizes de covariância dos grupos, além da generalização para efeitos não lineares nos centroides. É importante comentar que toda a implementação do CEM-Co foi construída e está disponível de forma open source no software $R$.

Toda a estrutura necessária para a estimação dos parâmetros do CEM-Co, incluindo a estimação do número de grupos e um teste de razão de verossimilhança para verificar se realmente há efeitos de covariáveis, foi desenvolvida. Assim, disponibilizamos um pacote completo para a aplicação prática do CEM-Co.

Adicionalmente, algumas propriedades conhecidas do algoritmo CEM, como a monotonicidade e convergência para uma sequência estacionária, foram estendidas para o algoritmo CEM-Co.

Utilizando um amplo estudo de simulações, foi possível identificar melhorias na estruturas dos grupos gerados com o CEM-Co em relação a algumas opções existentes na literatura. Também apresentamos a eficiência do critério BIC para a estimação do número de grupos. Para o teste de razão de verossimilhança, concluímos que o erro do tipo I é controlado quando o número de observações é suficiente, além de ter um poder de teste adequado. Para aplicações com tamanho amostral pequeno, apresentamos um teste baseado em bootstrap que controla melhor o erro do tipo I. 
Na aplicação prática, em que utilizamos dados de expressão gênica de câncer de pulmão NSCLC do estágio I, mostramos que o CEM-Co foi o único algoritmo, dentre os quatro testados, capaz de encontrar um subgrupo com taxa de sobrevida menor após controle de todas as covariáveis em um modelo de sobrevivência de Cox. Tal resultado indica que há possibilidade de um estudo mais detalhado desse grupo de pacientes para a criação de um novo tratamento, visto que os atuais parecem não funcionar para esses pacientes que apresentam expressões gênicas diferentes.

Com a teoria, as formas de estimação e os resultados apresentados nas simulações e dados reais, acreditamos que o algoritmo CEM-Co seja uma ferramenta útil para a criação de grupos, controlando por efeitos de covariáveis tanto nos centroides quanto nas matrizes de covariância, e que possa ser utilizada em diversas aplicações práticas.

\subsection{Próximos Passos}

Acreditamos que para deixar o CEM-Co ainda mais genérico, seria interessante estendê-lo para diferentes parametrizações das matrizes de covariância. O ideal seria estender para as mesmas estruturas já utilizadas para o CEM [28].

Neste trabalho, desenvolvemos o CEM-Co com a estrutura mais complexa. Ter a possibilidade de estimarmos com parametrizações mais simples, embora aumente as suposições do modelo, pode ser útil para situações em que o número de graus de liberdade (situações com poucas observações) é restrito. Tal crença deriva-se da conclusão de que os parâmetros necessários para estimar as matrizes de covariância livres, isto é, sem nenhuma suposição, é alto.

Outra possibilidade que acreditamos ser de interesse prático é a extensão do CEM-Co para utilizar outras distribuições multivariadas ao invés de apenas considerar a normal multivariada. Por exemplo: para situações em que os dados apresentem mais outliers, pode ser interessante o uso de distribuições multivariadas com caudas mais pesadas (como a distribuição t de Student multivariada).

Acreditamos também que seria interessante a implementação do CEM-Co em alguma linguagem de baixo nível para acelerar o processo de estimação.

Por fim, a análise de resíduos e de sensibilidade para identificar se o agrupa- 
mento é muito afetado por pequenas perturbações também pode ser algo interessante, além de aplicarmos correções na estatística da razão de verossimilhanças para poucas amostras. 


\section{Referências}

[1] Mohamed N Ahmed, Sameh M Yamany, Nevin Mohamed, Aly A Farag, and Thomas Moriarty. A modified fuzzy c-means algorithm for bias field estimation and segmentation of mri data. IEEE transactions on medical imaging, 21(3):193-199, 2002.

[2] Preeti Arora, Shipra Varshney, et al. Analysis of k-means and k-medoids algorithm for big data. Procedia Computer Science, 78:507-512, 2016.

[3] Tihomir Asparouhov and Bengt Muthén. Auxiliary variables in mixture modeling: Three-step approaches using m plus. Structural Equation Modeling: A Multidisciplinary Journal, 21(3):329-341, 2014.

[4] Karen Bandeen-Roche, Diana L Miglioretti, Scott L Zeger, and Paul J Rathouz. Latent variable regression for multiple discrete outcomes. Journal of the American Statistical Association, 92(440):1375-1386, 1997.

[5] Vladimir Batagelj. Generalized ward and related clustering problems. Classification and related methods of data analysis, pages 67-74, 1988.

[6] James C Bezdek, Robert Ehrlich, and William Full. Fcm: The fuzzy c-means clustering algorithm. Computers \& Geosciences, 10(2-3):191-203, 1984.

[7] Annabel Bolck, Marcel Croon, and Jacques Hagenaars. Estimating latent structure models with categorical variables: One-step versus three-step estimators. Political Analysis, 12(1):3-27, 2004.

[8] Tadeusz Caliński and Jerzy Harabasz. A dendrite method for cluster analysis. Communications in Statistics-theory and Methods, 3(1):1-27, 1974.

[9] Gilles Celeux and Gérard Govaert. A classification em algorithm for clustering and two stochastic versions. Computational statistics \& Data analysis, 14(3):315-332, 1992.

[10] Gilles Celeux and Gérard Govaert. Gaussian parsimonious clustering models. Pattern recognition, 28(5):781-793, 1995. 
[11] Kin-Pong Chan and Ada Wai-Chee Fu. Efficient time series matching by wavelets. In Data Engineering, 1999. Proceedings., 15th International Conference on, pages 126-133. IEEE, 1999.

[12] Pak K Chan, Martine DF Schlag, and Jason Y Zien. Spectral k-way ratio-cut partitioning and clustering. IEEE Transactions on Computer-Aided Design of Integrated Circuits and Systems, 13(9):1088-1096, 1994.

[13] Yizong Cheng. Mean shift, mode seeking, and clustering. IEEE transactions on pattern analysis and machine intelligence, 17(8):790-799, 1995.

[14] Clifford C Clogg. New developments in latent structure analysis. Factor analysis and measurement in sociological research, 1981.

[15] Dorin Comaniciu and Peter Meer. Mean shift: A robust approach toward feature space analysis. IEEE Transactions on pattern analysis and machine intelligence, 24(5):603-619, 2002.

[16] Marcella Corduas and Domenico Piccolo. Time series clustering and classification by the autoregressive metric. Computational Statistics \& Data Analysis, 52(4):1860-1872, 2008.

[17] Christina Curtis, Sohrab P Shah, Suet-Feung Chin, Gulisa Turashvili, Oscar M Rueda, Mark J Dunning, Doug Speed, Andy G Lynch, Shamith Samarajiwa, Yinyin Yuan, et al. The genomic and transcriptomic architecture of 2,000 breast tumours reveals novel subgroups. Nature, 486(7403):346, 2012.

[18] Shaheenah Dawood, Kristine Broglio, Aman U Buzdar, Gabriel N Hortobagyi, and Sharon H Giordano. Prognosis of women with metastatic breast cancer by her2 status and trastuzumab treatment: an institutional-based review. Journal of clinical oncology, 28(1):92, 2010.

[19] C Mitchell Dayton and George B Macready. Concomitant-variable latentclass models. Journal of the American Statistical Association, 83(401):173$178,1988$. 
[20] Carl De Boor. On calculating with b-splines. Journal of Approximation theory, 6(1):50-62, 1972.

[21] Michiel JL de Hoon, Seiya Imoto, John Nolan, and Satoru Miyano. Open source clustering software. Bioinformatics, 20(9):1453-1454, 2004.

[22] Dariusz Dereniowski and Marek Kubale. Cholesky factorization of matrices in parallel and ranking of graphs. In International Conference on Parallel Processing and Applied Mathematics, pages 985-992. Springer, 2003.

[23] Jonathan D'Cunha, James E Herndon II, Debra L Herzan, G Alexander Patterson, Leslie J Kohman, David H Harpole, Kemp H Kernstine, Jeffrey A Kern, Mark R Green, Michael A Maddaus, et al. Poor correspondence between clinical and pathologic staging in stage 1 non-small cell lung cancer: results from calgb 9761, a prospective trial. Lung Cancer, 48(2):241-246, 2005.

[24] Pierpaolo D'Urso and Elizabeth Ann Maharaj. Autocorrelation-based fuzzy clustering of time series. Fuzzy Sets and Systems, 160(24):3565-3589, 2009.

[25] Martin Ester, Hans-Peter Kriegel, Jörg Sander, Xiaowei Xu, et al. A densitybased algorithm for discovering clusters in large spatial databases with noise. In $K d d$, volume 96, pages 226-231, 1996.

[26] BS Everitt, S Landau, and M Leese. Cluster analysis. 2001. Arnold, London, 2001.

[27] Chris Fraley and Adrian E Raftery. Model-based clustering, discriminant analysis, and density estimation. Journal of the American statistical Association, 97(458):611-631, 2002.

[28] Chris Fraley, Adrian E Raftery, T Brendan Murphy, and Luca Scrucca. mclust version 4 for $\mathrm{r}$ : normal mixture modeling for model-based clustering, classification, and density estimation. Technical report, Technical report, 2012. 
[29] André Fujita, Daniel Y Takahashi, and Alexandre G Patriota. A nonparametric method to estimate the number of clusters. Computational Statistics \& Data Analysis, 73:27-39, 2014.

[30] André Fujita, Daniel Y Takahashi, Alexandre G Patriota, and João R Sato. A non-parametric statistical test to compare clusters with applications in functional magnetic resonance imaging data. Statistics in medicine, 33(28):4949-4962, 2014.

[31] Isobel Claire Gormley and Sylvia Frühwirth-Schnatter. Mixture of experts models. Handbook of Mixture Analysis, pages 271-307, 2019.

[32] Dereje W Gudicha and Jeroen K Vermunt. Mixture model clustering with covariates using adjusted three-step approaches. In Algorithms from and for Nature and Life, pages 87-94. Springer, 2013.

[33] Jacques A Hagenaars and Allan L McCutcheon. Applied latent class analysis. Cambridge University Press, 2002.

[34] John A Hartigan and Manchek A Wong. Algorithm as 136: A k-means clustering algorithm. Journal of the Royal Statistical Society. Series C (Applied Statistics), 28(1):100-108, 1979.

[35] Robert V Hogg, Joseph McKean, and Allen T Craig. Introduction to mathematical statistics. Pearson Education, 2005.

[36] Tao Huang, Heng Peng, and Kun Zhang. Model selection for gaussian mixture models. arXiv preprint arXiv:1301.3558, 2013.

[37] Lawrence Hubert and Phipps Arabie. Comparing partitions. Journal of classification, 2(1):193-218, 1985.

[38] Salvatore Ingrassia, Simona C Minotti, and Giorgio Vittadini. Local statistical modeling via a cluster-weighted approach with elliptical distributions. Journal of classification, 29(3):363-401, 2012.

[39] Paul Jaccard. Etude comparative de la distribution florale dans une portion des Alpes et du Jura. Impr. Corbaz, 1901. 
[40] Wagner A Kamakura, Michel Wedel, and Jagadish Agrawal. Concomitant variable latent class models for conjoint analysis. International Journal of Research in Marketing, 11(5):451-464, 1994.

[41] Akihito Kamata, Yusuf Kara, Chalie Patarapichayatham, and Patrick Lan. Evaluation of analysis approaches for latent class analysis with auxiliary linear growth model. Frontiers in psychology, 9:130, 2018.

[42] Leonard Kaufman and Peter Rousseeuw. Clustering by means of medoids. North-Holland, 1987.

[43] Wojtek J Krzanowski and YT Lai. A criterion for determining the number of groups in a data set using sum-of-squares clustering. Biometrics, pages 23-34, 1988

[44] Andrea E Lamont, Jeroen K Vermunt, and M Lee Van Horn. Regression mixture models: Does modeling the covariance between independent variables and latent classes improve the results? Multivariate behavioral research, 51(1):35-52, 2016.

[45] T Warren Liao. Clustering of time series data - a survey. Pattern recognition, 38(11):1857-1874, 2005.

[46] Kenneth J Livak and Thomas D Schmittgen. Analysis of relative gene expression data using real-time quantitative pcr and the 2 - $\delta \delta$ ct method. methods, 25(4):402-408, 2001.

[47] James MacQueen et al. Some methods for classification and analysis of multivariate observations. In Proceedings of the fifth Berkeley symposium on mathematical statistics and probability, volume 1, pages 281-297. Oakland, CA, USA., 1967.

[48] Antonello Maruotti and Maurizio Vichi. Time-varying clustering of multivariate longitudinal observations. Communications in Statistics-Theory and Methods, 45(2):430-443, 2016.

[49] Saeed Masoudnia and Reza Ebrahimpour. Mixture of experts: a literature survey. Artificial Intelligence Review, 42(2):275-293, 2014. 
[50] Andrew McCallum, Kamal Nigam, and Lyle H Ungar. Efficient clustering of high-dimensional data sets with application to reference matching. In Proceedings of the sixth ACM SIGKDD international conference on Knowledge discovery and data mining, pages 169-178. ACM, 2000.

[51] Geoffrey McLachlan and Thriyambakam Krishnan. The EM algorithm and extensions, volume 382. John Wiley \& Sons, 2007.

[52] Geoffrey J McLachlan and Kaye E Basford. Mixture models. inference and applications to clustering. Statistics: Textbooks and Monographs, New York: Dekker, 1988, 1, 1988.

[53] Marina Meilă and William Pentney. Clustering by weighted cuts in directed graphs. In SIAM Conference on Data Mining (SDM). Retrieved February, volume 1, page 2008. SIAM, 2007.

[54] Glenn W Milligan and Martha C Cooper. An examination of procedures for determining the number of clusters in a data set. Psychometrika, 50(2):159179, 1985.

[55] Glenn W Milligan and Martha C Cooper. A study of the comparability of external criteria for hierarchical cluster analysis. Multivariate Behavioral Research, 21(4):441-458, 1986.

[56] Meinard Müller. Dynamic time warping. Information retrieval for music and motion, pages 69-84, 2007.

[57] Keefe Murphy and Thomas Brendan Murphy. Gaussian parsimonious clustering models with covariates. arXiv preprint arXiv:1711.05632, 2017.

[58] Keefe Murphy and Thomas Brendan Murphy. Gaussian parsimonious clustering models with covariates and a noise component. Advances in Data Analysis and Classification, pages 1-33, 2019.

[59] Karen Nylund-Gibson, Ryan Grimm, Matt Quirk, and Michael Furlong. A latent transition mixture model using the three-step specification. Structural Equation Modeling: A Multidisciplinary Journal, 21(3):439-454, 2014. 
[60] Tim Oates, Laura Firoiu, and Paul R Cohen. Clustering time series with hidden markov models and dynamic time warping. In Proceedings of the IJCAI-99 workshop on neural, symbolic and reinforcement learning methods for sequence learning, pages 17-21. Citeseer, 1999.

[61] Pieter E Postmus, Henk H Berendsen, Nico van Zandwijk, Ted AW Splinter, Jos Th M Burghouts, Wim Bakker, and EORTC Lung Cancer Cooperative Group. Retreatment with the induction regimen in small cell lung cancer relapsing after an initial response to short term chemotherapy. European Journal of Cancer and Clinical Oncology, 23(9):1409-1411, 1987.

[62] Li-Xuan Qin and Steven G Self. The clustering of regression models method with applications in gene expression data. Biometrics, 62(2):526-533, 2006.

[63] William M Rand. Objective criteria for the evaluation of clustering methods. Journal of the American Statistical association, 66(336):846-850, 1971.

[64] Carlos Eduardo M Relvas and Gilberto A Paula. Partially linear models with first-order autoregressive symmetric errors. Statistical Papers, 57(3):795$825,2016$.

[65] Peter J Rousseeuw. Silhouettes: a graphical aid to the interpretation and validation of cluster analysis. Journal of computational and applied mathematics, 20:53-65, 1987.

[66] Cornelia Savu and Mark Trede. Hierarchies of archimedean copulas. Quantitative Finance, 10(3):295-304, 2010.

[67] Thomas D Schmittgen and Kenneth J Livak. Analyzing real-time pcr data by the comparative c t method. Nature protocols, 3(6):1101, 2008.

[68] Robert H Shumway and David S Stoffer. Time series analysis and its applications: with $R$ examples. Springer Science \& Business Media, 2010.

[69] Catherine A Sugar and Gareth M James. Finding the number of clusters in a dataset. Journal of the American Statistical Association, 2011. 
[70] Sergios Theodoridis and Konstantinos Koutroumbas. Pattern Recognition, Fourth Edition. Academic Press, 4th edition, 2008.

[71] Robert Tibshirani and Guenther Walther. Cluster validation by prediction strength. Journal of Computational and Graphical Statistics, 14(3):511-528, 2005.

[72] Robert Tibshirani, Guenther Walther, and Trevor Hastie. Estimating the number of clusters in a data set via the gap statistic. Journal of the Royal Statistical Society: Series B (Statistical Methodology), 63(2):411-423, 2001.

[73] Lindsey A Torre, Rebecca L Siegel, and Ahmedin Jemal. Lung cancer statistics. In Lung cancer and personalized medicine, pages 1-19. Springer, 2016.

[74] Peter GM Van der Heijden, Jos Dessens, and UIf Bockenholt. Estimating the concomitant-variable latent-class model with the em algorithm. Journal of Educational and Behavioral Statistics, 21(3):215-229, 1996.

[75] Jeroen K Vermunt. Latent class modeling with covariates: Two improved three-step approaches. Political analysis, 18(4):450-469, 2010.

[76] Jeroen K Vermunt and Jay Magidson. Latent class cluster analysis. Applied latent class analysis, 11:89-106, 2002.

[77] Jeroen K Vermunt and Jay Magidson. Latent gold 4.0 user's guide. Applied latent class analysis, 2005.

[78] Maciel Calebe Fujita Vidal, Joao Ricardo Sato, Joana Bisol Balardin, Daniel Yasumasa Takahashi, and Andre Fujita. Anocva in r: a software to compare clusters between groups and its application to the study of autism spectrum disorder. Frontiers in Neuroscience, 11:16, 2017.

[79] Charles L Vogel, Melody A Cobleigh, Debu Tripathy, John C Gutheil, Lyndsay N Harris, Louis Fehrenbacher, Dennis J Slamon, Maureen Murphy, William F Novotny, Michael Burchmore, et al. Efficacy and safety of trastuzumab as a single agent in first-line treatment of her2-overexpressing metastatic breast cancer. Journal of clinical oncology, 20(3):719-726, 2002. 
[80] Ulrike Von Luxburg. A tutorial on spectral clustering. Statistics and computing, 17(4):395-416, 2007.

[81] Joe H Ward Jr. Hierarchical grouping to optimize an objective function. Journal of the American statistical association, 58(301):236-244, 1963.

[82] Samuel S Wilks. The large-sample distribution of the likelihood ratio for testing composite hypotheses. The Annals of Mathematical Statistics, 9(1):60$62,1938$.

[83] John H Wolfe. Pattern clustering by multivariate mixture analysis. Multivariate Behavioral Research, 5(3):329-350, 1970.

[84] CF Jeff Wu et al. On the convergence properties of the em algorithm. The Annals of statistics, 11(1):95-103, 1983.

[85] Zhenyu Wu and Richard Leahy. An optimal graph theoretic approach to data clustering: Theory and its application to image segmentation. IEEE transactions on pattern analysis and machine intelligence, 15(11):11011113, 1993.

[86] Kazuo Yamaguchi. Multinomial logit latent-class regression models: An analysis of the predictors of gender-role attitudes among japanese women. American Journal of Sociology, 105(6):1702-1740, 2000.

[87] Ka Yee Yeung, Chris Fraley, Alejandro Murua, Adrian E. Raftery, and Walter L. Ruzzo. Model-based clustering and data transformations for gene expression data. Bioinformatics, 17(10):977-987, 2001.

[88] Ka Yee Yeung and Walter L Ruzzo. Details of the adjusted rand index and clustering algorithms, supplement to the paper "an empirical study on principal component analysis for clustering gene expression data". Bioinformatics, 17(9):763-774, 2001. 